\title{
SOCIAL SECURITY AND DEMOGRAPHIC UNCERTAINTY: THE RISK SHARING PROPERTIES OF ALTERNATIVE POLICIES
}

\author{
Henning Bohn
}

Working Paper 7030

http://www.nber.org/papers/w7030

\author{
NATIONAL BUREAU OF ECONOMIC RESEARCH \\ 1050 Massachusetts Avenue \\ Cambridge, MA 02138 \\ March 1999
}

Paper prepared for the NBER Conference on Risk Aspects of Investment Based Social Security Reform, January 15-16, 1999; Revised Version. The views expressed in this paper are those of the authors and do not reflect those of the National Bureau of Economic Research.

(C) 1999 by Henning Bohn. All rights reserved. Short sections of text, not to exceed two paragraphs, may be quoted without explicit permission provided that full credit, including $(\mathcal{C}$ notice, is given to the source. 
Social Security and Demographic Uncertainty:

The Risk Sharing Properties of Alternative Policies

Henning Bohn

NBER Working Paper No. 7030

March 1999

\begin{abstract}
As the U.S. population ages, the growing retiree-worker ratio increases the burden of public retirement systems. Is it efficient to maintain a defined benefit social security system? Should PAYGO benefits be reduced and private retirement savings be encouraged? The paper examines these questions in a neoclassical growth model with overlapping generations and demographic uncertainty. In case of shocks to the birth rate, I find that a defined-benefits social security system is more efficient ex-ante than a defined-contribution or privatized system. This is because small cohorts generally enjoy favorable wage and interest rate movements. They are in the labor force when the capital-labor ratio is high and they earn capital income when the capital-labor ratio is low. A defined benefit system helps to offset the effect of these factor price movements by imposing higher taxes on small cohorts. Neither defined-benefits nor its main alternative are fully efficient, however, because they all fail to adjust current retiree benefits in response to anticipated future demographic changes. In case of changes in life-expectancy, the efficient policy response depends on the predictability of deaths at the individual level and on the availability of annuities. Reduced benefits can be efficient if annuities markets are missing and the mortality change is such that accidental bequests decline, but not otherwise.
\end{abstract}

Henning Bohn

Department of Economics

University of California at Santa Barbara

Santa Barbara, CA 93106

bohn@econ.ucsb.edu 


\section{Introduction}

All over the world, declining population growth rates and rising life expectancy are creating problems for public retirement systems. With a constant population structure, a pay-as-you-go (PAYGO) social security system could operate at constant tax and replacement rates. But when the ratio of retirees to workers rises, either tax rates must be raised or the replacement rate must be reduced. These demographic changes are the driving force for the current social security reform debate.

This paper considers the design of social security from an ex ante perspective. Once a demographic shock is realized, a debate on how to adjust taxes and benefits is necessarily a distributional debate. A lighter burden on one generation implies a heavier burden on other generations. From an ex ante perspective, in contrast, demographics is a stochastic process and the design questions are about risk sharing. Different realizations of birth rates and survival rates have an impact on the financial status of government programs and, more broadly, on the set of feasible allocations of national resources. Policy questions are then questions of efficiency rather than redistribution: How can the financial risks created by demographic uncertainty be shared by different generations? What are the risk-sharing implications of alternative policy rules? Moreover, we can evaluate specific policy actions ("reforms") taken in response to demographic changes in terms of whether or not they represent efficient responses to the underlying shocks.

I examine demographic changes in a Diamond (1965) style neoclassical growth model with overlapping generations, building on Bohn (1998a). Government policy is potentially welfare improving because future generations are naturally excluded from financial markets. They cannot 
insure themselves against macroeconomic or demographic risks.1 In this setting, I characterize the general properties of alternative social security systems, with a focus on four specific alternatives: A PAYGO social security systems with defined benefits (DB), a PAYGo system with defined contributions (DC), a private/privatized system, and a "conditionally prefunded" system.

The two PAYGo systems are relevant because existing social security systems in many developed countries are pure PAYGO systems, including the U.S. until 1983. If the worker-retiree ratio is constant, DB and DC are observationally equivalent. But when the retiree-worker ratio rises, the key issue for PAYGo social security is if taxes are held constant and benefits are reduced or if benefits are held constant and taxes are increased. This choice is at the heart of the current U.S. policy debate.

The analysis of a privatized system is motivated by the current discussion about systems in which individuals fund their own retirement, at least in part. A fully privatized system represents this policy option in pure form. ${ }^{2}$

Finally, the "conditionally prefunded" social security system is intended to capture key features of the post-1983 U.S. system. The U.S. social security debate is heavily influenced by the social security Administration's 75-year extrapolations of current policy. Whenever the 75year forecast shows a significant revenue gap, public pressure seems to arise to reform the system. ${ }^{3}$ If one takes this linkage seriously and

1 To simplify, I abstract from private risk sharing and from Ricardian bequests.

2 some of the privatization literature distinguishes between private savings without government intervention and "privatized" social security, meaning a funded system that is mandatory and government-regulated. For the intergenerational issues in this paper, this distinction is irrelevant.

3 For example, the 1983 reform was supposed to cover the then-existing revenue gap through tax increases that would accumulate a trust fund sufficient to carry social security through the years of baby boom retirement. Much of the current debate is also about closing the projected funding gap. 


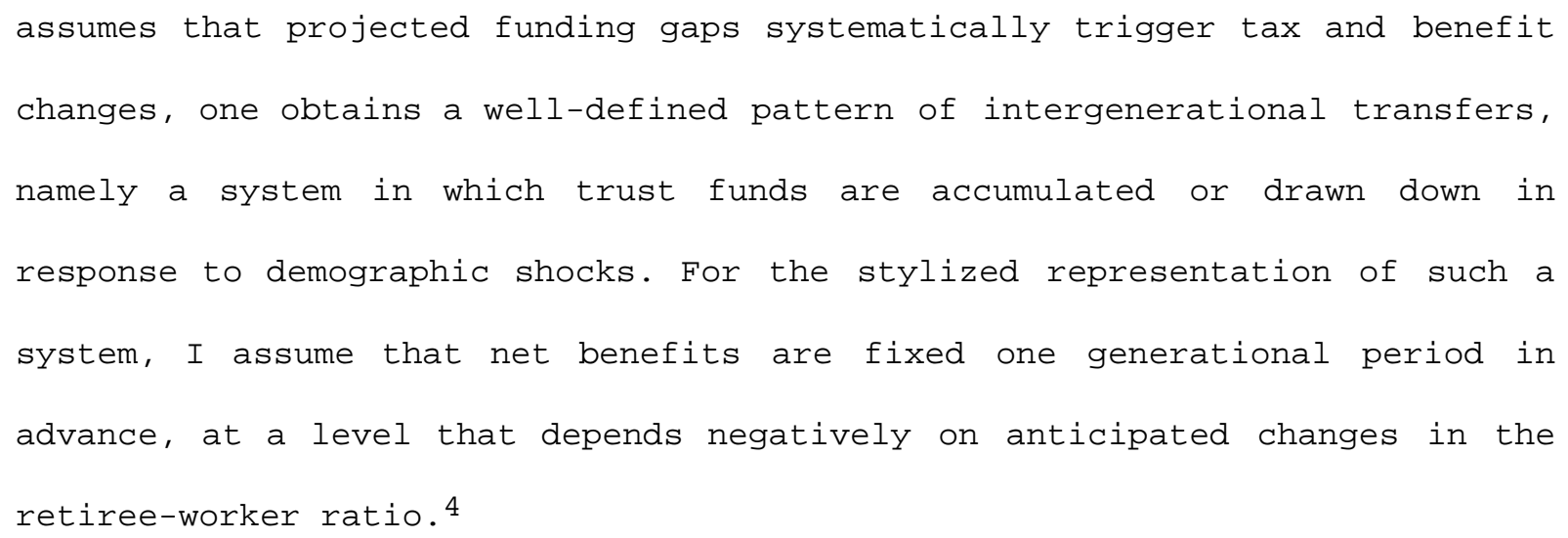

\footnotetext{
4 There is an apparent consensus that benefit changes ought to be phased in slowly and that the benefits of current retirees are untouchable. The reform debate is about varying FUTURE benefit levels in response to anticipated demographic pressures, not about moving to a true PAYGO-DC system with variable benefits to current retirees. McHale (1999) suggests that social security reforms in other countries follow a similar pattern.
} 
In the model, the magnitude of the factor price effects relative to the fiscal burden depends on the elasticity of factor substitution and on the level of social security taxes. With Cobb-Douglas technology (as benchmark), the factor price effects dominate if the ratio of tax rate ( $\theta$ ) to one minus the tax rate, $\theta /(1-\theta)$, is below the capital share in output. For the U.S., this condition is satisfied by a wide margin, suggesting that the factor price effects of birth rate changes should dominate the fiscal effects. The current debate about social security reform, in contrast, focuses on fiscal pressures and virtually ignores factor price effects. 5

One may wonder, of course, to what extent the results from the twoperiod model are empirically realistic. The empirical evidence is unfortunately very limited, largely because it takes decades of data to obtain a single generation-length observation. Empirical evidence in related areas--cross country growth and studies of relative wages-suggests, however, that demographic changes have wage effects broadly consistent with the OG model (see Section 6).

The second set of results is about unexpected changes in old-age mortality. The implications for the allocation of risk depend significantly on the individual predictability of death, on the availability of fair annuities, and on who might receive any accidental bequests. Under a variety of assumptions, lower old-age mortality increases the need for retirement consumption. The efficient response to a longer retirement period is then to increase social security benefits. This argument applies,

5 The Social Security Administration's long run projections of the social security system's financial status are, for example, based on extrapolating historical trends. Neither the linkage between cohort size and factor prices nor the insurance role of DB social security are new ideas. Easterlin (1987) provides much broader arguments about the advantages of being in a small cohort. Smith (1982) provides a numerical example illustrating the insurance role of DB social security. The point here is that the factor price effects are large relative to the fiscal effects under empirically plausible assumptions and therefore important for social security reform. 
if deaths are individually foreseeable or if savings are annuitized, so that accidental bequests are small, or if accidental bequests are distributed within a cohort. Reduced benefits might be efficient, however, if lower old-age mortality reduces the accidental bequests received by workers. 6

Third, a comparison of alternative policies shows that a fully privatized system has essentially the same risk-sharing properties as a defined-contribution PAYGO system. This is because neither a DC-PAYGO nor a privatized system impose higher taxes on the young when the worker retireeworker ratio rises, whereas a DB system does. For risk-sharing purposes, a partially-privatized system (say, combining a smaller DC plan with individual accounts) is therefore equivalent to a mixture of a DB and DC system. A conditionally-funded DB system mimics a partially-privatized system with regard to anticipated demographic changes, but it behaves like a pure DB system when unexpected changes occur.

Fourth, none of the above systems is fully efficient. Efficient policy responses (if any) should take place as soon as a demographic shock is revealed. Moreover, efficiency requires that all risks are shared by all generations, making no exception for current retirees. This requirement is violated by DB and DC systems because both fail to vary current retiree benefits in anticipation of future changes in the retiree-worker ratio, e.g., when the current birthrate changes. I have argued elsewhere (Bohn 1998b) that the political viability of social security requires at least a one-period-ahead commitment to retiree benefits (see also McHale 1999 ).

\footnotetext{
6 In the current reform debate, increased longevity is often cited to justify an increased "normal" retirement age, i.e., reduced benefits for a given retirement age. Some proposals even call for an indexing of the retirement age to life-expectancy. The efficiency considerations of this paper provide support for such proposals only if the accidental bequest channel is empirically important. This is an open question.
} 
This may explain why the political debate takes for granted that current retirees are exempt from reforms. From a risk-sharing perspective, such an exemption is nonetheless a glaring inefficiency.

Though this paper focuses on demographic risks, I should briefly comment on other sources of uncertainty, notably on productivity risk and stock market risk. ${ }^{7}$ Productivity shocks are arguably the most important source of long-run uncertainty about wages and capital income (Bohn 1998c). In an OG setting, productivity risk is not necessarily allocated efficiently across cohorts. Policy tools such as government debt and social security implicitly shift risk across cohorts (Bohn 1998a). Social security, especially a wage-indexed system, has an important role in this context, because it provides a means of intergenerational redistribution that is more "neutral" with regard to risk-shifting than government debt.

Stock market risk has recently received considerable attention in the social security literature. Here one should distinguish work on "privatized" retirement (investment options in "individual accounts") from work on intergenerational risk sharing through the social security trust fund. Individual accounts are essentially irrelevant from a generational perspective because the returns accrue to the contributors (Bohn 1997). Trust fund investments, on the other hand, re-allocate risk across generations, because future tax payers are the residual claimants in any DB system. Bohn (1997, 1988c), Smetters (1997, 1999), Shiller (1998), and Abel (1998, 1999) discuss some of the positive and normative implications of alternative trust fund investments. This paper abstracts from most financial market issues to focus on demographics. But I include a simple

7 There is also a huge literature on how social security helps to share individual-level risks such as disability, mortality, and cross-sectional income uncertainty (see, e.g., Storesletten et al. 1998). Such risks may well be responsible for the existence and popularity of social security, but they are beyond the scope of this paper. 
productivity shock to demonstrate that shocks to the labor force have very different welfare implications than productivity shocks even though both have the same impact on effective capital-labor ratio. The productivity shock also illustrates how easily other shocks could be added.

The paper is organized as follows. Section 2 describes the model. Section 3 examines the risk sharing implications of alternative social security policies. Section 4 studies the implications of missing annuities markets and of accidental bequests. Section 5 derives necessary conditions for efficient risk sharing and their implications for social security policy. Section 6 comments on extensions of the model and on empirical issues. Section 7 concludes.

\section{A Model with Stochastic Population Growth}

This section examines risk sharing in a modified Diamond (1965)-style OG model with stochastic population growth and stochastic total factor productivity.

\subsection{Population Dynamics and Preferences}

In the Diamond model, generation $t$ enters as working-age adults in period $t$ and retires in period $t+1$. For modeling demographic uncertainty, it is important, however, that individuals are born long before they enter the labor force. In terms of generational time units, society has about one period advance notice about changes in the retiree-worker ratio. Hence, I will assume that generation $t$ is born in period $t-1$, works in period $t$, and retires in period $t+1$. At time $t, N_{t}$ is the number of generation $t+1$ children, $\mathrm{N}^{\mathrm{W}}$ the number of generation $t$ workers, and $\mathrm{N}_{t}$ the number of generation $t-1$ retirees. 
To limit the scope of the paper, I assume throughout that childbearing is exogenous. Each of the $\mathrm{N}^{W_{t}}$ workers of generation $t$ has $b_{t}$ children, so that ${ }_{N} C_{t}=N^{W_{t}} \cdot b_{t}$. To make the future workforce somewhat unpredictable, I assume that only a fraction $\mu_{1 t+1}$ of children survives into adulthood. 8 Then the growth rate of the workforce, $\mathrm{N}_{t+1}^{\mathrm{W}_{t+1}} \mathrm{~N}_{t}=\mu_{1 t+1} \cdot \mathrm{N}_{t} / \mathrm{N}^{\mathrm{W}} t=$ $\mu_{1 t+1} \cdot b_{t}=1+n_{t+1}$, is partially predictable, but not perfectly. The variables $\mu_{1 t}$ (survival rate) and bt (birth rate) are assumed i.i.d. Throughout, individuals in a cohort are identical, individual survival probabilities equal the aggregate survival rate, and all variables are treated as continuous, including $b_{t}$.

Parents care about their children's consumption when the children live in their household. Their preferences do not include an altruistic bequest motive, however. This assumption is important because fiscal policy would be irrelevant if all generations were linked through Ricardian bequests. Since Altonji et al. (1996) find that private intergenerational risk sharing is highly imperfect empirically, it is a reasonable assumption in this context. Bequests may nonetheless occur "accidentally" if mortality is stochastic and annuity markets are imperfect, as I will explain below.

Parents make decisions about their own consumption ${ }^{{ }^{W}}{ }_{t}$ and about their childrens' consumption $\mathrm{C}^{0} t$ (per child). Throughout, I assume homothetic (CRRA) preferences to obtain balanced growth. Let

$$
u^{1} t=\frac{1}{1-\eta} \cdot\left[\rho^{W} \cdot\left(c^{W}\right)^{1-\eta}+b_{t} \cdot \rho_{0}\left(b_{t}\right) \cdot\left(c^{0} t\right)^{1-\eta}\right]
$$

be the parent's period-t utility, where $\eta>0$ is the inverse elasticity of intertemporal substitution. The per-child weight $\rho_{0}\left(b_{t}\right)$ may depend on the number of children: it seems reasonable to assume that $0<\rho_{0}\left(b_{t}\right) \leq \rho^{W}$ and that

8 otherwise, $\mathrm{N}^{\mathrm{W}}{ }_{t+1}=\mathrm{N}^{\mathrm{C}} \mathrm{t}$ would be known at time $t$. One may also interpret $\mu_{1 \mathrm{t}+1}$ as reflecting uncertainty about immigration. But since immigration would raise subtle welfare questions (how to include immigrants in the welfare function), I will not address immigration explicitly and interpret all uncertainty about $\mathrm{N}^{\mathrm{W}}{ }_{t+1}$ as survival uncertainty. 
$b_{t} \cdot \rho_{0}\left(b_{t}\right)$ is non-decreasing in the number of children. For any level of household consumption $c^{1} t=c^{W_{t}}+b_{t} \cdot c^{0} t$, the parent's optimality condition $b_{t} \cdot \rho^{W} \cdot\left(c^{W}\right)^{-\eta}=\rho_{0}\left(b_{t}\right) \cdot\left(c^{0} t\right)^{-\eta}$ then implies that $u^{1} t$ can be written as an

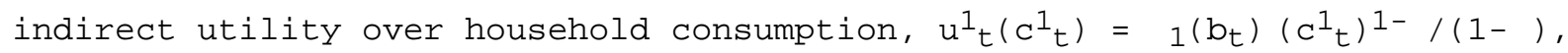
where $\rho_{1}\left(b_{t}\right)=\rho^{W} \cdot\left[1+b_{t} \cdot\left(\rho_{0}\left(b_{t}\right) / b_{t} / \rho^{W}\right)^{1 / \eta}\right] \eta$ depends on the number of children. Under the assumptions above, the elasticity of the weight $\rho_{1}$ with respect to the birth rate, $\gamma_{\rho}=\partial \rho_{1} / \partial b_{t} \cdot\left(b_{t} / \rho_{1}\right)$, is in the interval $0 \leq \gamma_{\rho} \leq \eta$.

Overall, children matter for the analysis for two reasons. Their birth provides advance notice about the size of future adult cohorts, and they affect their parents spending needs. Thus, the model accounts not only for old-age dependency but also for variations in youth-dependency. Otherwise, the model with children works just like Diamond's two-period oG model.

Now consider retirement. As old-age survival improves, more workers survive into the retirement period and those who survive live longer. For social security, these changes matter only through their combined impact on the ratio of retirees to workers. 9 For individual behavior, however, an anticipated longer life span may have different implications than a reduced probability of a sudden death. For a known life span, retiree consumption needs are presumably proportional to the length of the retirement period. Retiree consumption needs will also increase if the rate of unanticipated deaths declines in a setting with fair annuities. This is because individuals without bequest motive will place all their assets into annuities. The return on fair annuities is inversely related to the average

\footnotetext{
9 The two changes may have different effects if the social security replacement rate varies with age or if one accounts for Medicare. In the U.S., social security is fixed in real terms at retirement, so that the replacement rate tends to fall with age, but the value of Medicare is rising with age. In the model, the replacement rate is assumed constant within each generational period.
} 
survival rate. Hence, a rising survival rate will require more retirement savings to support a given consumption level, as in the case of a longer life span. If annuities are unavailable, however, or too expensive to be commonly used, a rising survival rate increases the probability that retirees can enjoy their savings. It mainly reduces accidental bequests and does not increase retirees resource requirements. These different cases have different policy implications and therefore deserve to be modeled carefully.

To capture a variable life-expectancy in the OG setting, I model the retirement period as a fractional period. At the start of period t, a fraction $1-\mu_{2 t}$ of all generation $t-1$ workers dies. The remainder, $\mu_{2 t}$, learns that they will live for a period of length $\phi_{t} \in(0,1]$. Both the survival probability and the conditional length of life have predictable and unanticipated components: $\mu_{2 t}=\mu_{2} e_{t-1} \cdot \mu_{2} u_{t}$ and $\phi_{t}=\phi^{e} e_{t-1} \cdot \phi^{u_{t}}$, where $\mu_{2} u_{t}$ and $\phi^{u_{t}}$ are i.i.d. shocks revealed at the start of period $t$, while $\mu_{2} e_{t-1}$ and $\phi^{e} e_{-1}$ are i.i.d. shocks revealed in period t-1.10 The product $\mu_{2} e_{t-1} \cdot \phi^{e}{ }_{t-1}$ may be interpreted as the life-expectancy at retirement. Conditional on survival, the period-t utility of the old is assumed proportional to the length of life, $u^{2} t+1=\phi_{t} \cdot\left(c^{2} t+1\right)^{1-\eta /(1-\eta) .11}$

Finally, generation $t^{\prime}$ s overall preferences combine the utility over working age consumption $u_{t}^{1}\left(c^{1} t\right)$ and retirement consumption $u^{2} t+1\left(c^{2} t+1\right)$,

10 For simplicity, I treat $\phi_{t}$ and $\mu_{2 t}$ as level-stationary even though technicalprogress in medical technology suggest an upward drift. Drift terms would require an analysis of "unbalanced" growth paths. This could be done (see Bohn 1998b for a deterministic analysis), but it would be cumbersome and not provide new insights about risk-sharing. Autocorrelation could also be accommodated, but it would not affect the main results and is therefore omitted.

11 one may interpret $\mathrm{u}_{t}{ }_{t}$ as an indirect utility obtained bymaximizing $\int_{0} \phi_{t}[c(s)] 1-\eta /(1-\eta)$ ds over a continuous consumption stream c(s), subject to a resource constraint limiting $\int \phi_{t} c(s) d s$. Implicitly, this abstracts from within-period interest and discounting. 


$$
\begin{aligned}
U_{t} & =I_{1 t} \cdot\left[u^{1} t\left(c^{1} t\right)+I_{2 t+1} \cdot \rho_{2} \cdot u^{2} t+1\left(c^{2} t+1\right)\right] \\
& =\frac{1}{1-\eta} \cdot I_{1 t} \cdot\left[\rho_{1}\left(b_{t}\right) \cdot\left(c^{1} t\right)^{1-\eta}+\rho_{2} \cdot \phi_{t+1} \cdot I_{2 t+1} \cdot\left(c^{2} t+1\right)^{1-\eta}\right],
\end{aligned}
$$

where the random variables $I_{1 t}$ and $I_{2 t+1}$ are $0-1$ indicators for individual survival into adulthood and retirement, and $\rho_{2}$ captures time preference. In expectation, $E\left[I_{1 t}\right]=E\left[\mu_{1 t}\right]=\mu_{1}$ and $E_{t}\left[\phi_{t+1} \cdot I_{2 t+1}\right]=\phi^{e} \cdot \mu_{2} e_{t}$ are equal to the respective aggregate values.

Overall, the population dynamics are such that the future labor force and the future worker-retiree ratio are quite predictable one period ahead, but not perfectly. This limited predictability is important for modeling social security because it motivates why policy reforms are debated with some lead time before demographic changes actually take place.

\subsection{The Macroeconomic setting}

The macroeconomic setting is intentionally kept simple to focus on the demographics. Each working-age person inelasticly supplies one unit of labor. Output is produced with capital $\mathrm{K}_{\mathrm{t}}$ and labor $\mathrm{N}^{\mathrm{W}}$,

$$
Y_{t}=K_{t} \alpha \cdot\left(A_{t} \cdot N^{W_{t}}\right)^{1-\alpha},
$$

where $\alpha$ is the capital share and $A_{t}$ is the economy's total factor productivity. Productivity follows a stochastic trend $A_{t}=\left(1+a_{t}\right) \cdot A_{t-1}$ with i.i.d. growth rate at. Capital depreciates at the rate $\delta$, implying a national resource constraint

$$
\mathrm{Y}_{t}+(1-\delta) \cdot \mathrm{K}_{t}=\mathrm{c}^{1} \mathrm{~N}^{\mathrm{W}} \mathrm{c}^{2}+\phi_{t} \cdot \mu_{2 t} \cdot \mathrm{N}^{\mathrm{W}}{ }_{t-1}+\mathrm{K}_{\mathrm{t}+1} \cdot
$$

Some extensions are examined in Section 6.12

The wage rate $\mathrm{w}_{t}=(1-\alpha) \cdot \mathrm{A}_{t} \cdot\left[\mathrm{K}_{\mathrm{t}} /\left(\mathrm{A}_{\mathrm{t}} \cdot \mathrm{N}^{\mathrm{W}}{ }_{t}\right)\right]^{\alpha}$ and the return on capital $\mathrm{R}_{t}$ $=\alpha \cdot\left[\mathrm{K}_{t} /\left(\mathrm{A}_{\mathrm{t}} \cdot \mathrm{N}_{\mathrm{t}}\right)\right]^{\alpha-1}+(1-\delta)$ both depend on the capital-labor ratio. Since $\mathrm{K}_{t}$ is known in period $t-1$, it is convenient to define the state variable $k_{t-1}=$

12 Bohn (1998a) has shown how this setting can be generalized, e.g., to include a variable labor supply, temporary productivity, CES-technology, and government spending, but such complicating features would be distracting here. 
$K_{t} /\left(A_{t-1} \cdot N^{W_{t-1}}\right)$ that scales the capital stock by lagged productivity and the lagged labor force. Wages and interest rates then depend on $\mathrm{k}_{\mathrm{t}-1}$, on current productivity growth, and on the current workforce growth.

To model policy, I abstract from all government activity but social security. 13 The government collects payroll taxes on wages $w_{t}$ at a rate $\theta_{t}$ from all workers and pays benefits to retirees at a replacement rate $\beta_{t}$. The cost of social security is the product of the number of surviving retirees, $\mathrm{N}^{\mathrm{R}_{t}}=\mu_{2 t} \cdot \mathrm{N}_{\mathrm{t}-1}$, their length of life $\phi_{t}$, and the level of benefit $\beta_{t} \cdot \mathrm{w}_{t}$. The system's revenues are $\theta_{t} \cdot \mathrm{w}_{t} \cdot \mathrm{N}^{\mathrm{W}}$. For given replacement rate $\beta_{t}$, the PAYGO budget constraint therefore implies a payroll tax rate of

$$
\theta_{t}=\beta_{t} \cdot \phi_{t} \cdot \mu_{2 t} \cdot \frac{\mathrm{N}^{W_{t-1}}}{\mathrm{~N}^{W_{t}}}=\beta_{t} \cdot \frac{\phi_{t} \cdot \mu_{2 t}}{\mathrm{~b}_{t-1} \cdot \mu_{1 t}} .
$$

The ratio $\left(\phi_{t} \cdot \mu_{2 t}\right) /\left(b_{t-1} \cdot \mu_{1 t}\right)$ can be interpreted as the "average" retireeworker ratio (after smoothing over $\phi_{t}$ ).

Interesting special cases of the PAYGO system are the defined-benefit (DB) system with $\beta_{t}=\beta^{*}$ and the defined-contribution (DC) system with $\theta_{t}=\theta^{*}$ and $\beta_{t}=\left(1+\mathrm{n}_{t}\right) /\left(\phi_{t} \cdot \mu_{2 t}\right) \cdot \theta^{*}$. Since individuals are not liquidity-constrained, government-mandated savings (sometimes called "privatized" or "individual accounts" systems) would simply reduce private savings (Bohn 1997). A privatized social security system is therefore equivalent to $\theta^{\star}=0$. In a mixed system consisting of individual accounts plus a PAYGO component, one should interpret $\theta_{t}$ and $\beta_{t}$ as the taxes and benefits of the PAYGo component. A system with government-run trust funds is somewhat more complicated, if the system promises benefits that do not depend on the performance of the trust fund (as in the U.S.). Generational accounting implies that each cohort's net benefits are equal to the system's PAYGo

13 This approach is nonetheless quite general because government transfers matter only through different cohorts' generational accounts. Hence, social security can be interpreted broadly as a stand-in for other intergenerational transfers. 
component, i.e., to the statutory benefits minus the proceeds from the trust fund built up by the same cohort's payroll taxes (see Bohn 1997). In the U.S., the buildup of the current trust fund started in 1983 in response to a funding gap in the Social security Administration's long run projections. Projected funding gaps are similarly influencing the current debate. Such gaps arise from two principal sources, rising life-expectancy and reduced birth rates. Hence, one may interpret the current U.S. system as a defined-benefits system that accumulates trust funds in response to either a rise in life-expectancy, $\mu_{2} e_{t} \cdot \phi^{e_{t}}$, and/or a fall in the birth rate $b_{t}$. Since a trust fund buildup is equivalent to a reduction in net benefits, such a "conditionally prefunded" system can represented parsimoniously by a benefit function $\beta_{t}=\beta\left(\mu_{2} e_{t}, \phi^{e} t, b_{t}\right)$ with $\partial \beta / \partial \mu_{2} e_{<0}$, $\partial \beta / \partial \phi^{e}<0$, and $\partial \beta / \partial \mathrm{b}>0$

McHale's (1999) analysis of recent pension reforms around the world suggests that a variable benefit function of this type is empirically realistic for other countries, too. In the countries studied by McHale, reforms were generally triggered by anticipated funding gaps. Benefits to current retirees remained virtually unchanged, but benefits to future generations were reduced. This implies a benefit function with the same features as in the conditionally prefunded system.

More generally, a variety of social security systems with and without prefunding can be reinterpreted as PAYGO systems with an appropriately state-contingent benefit function. Hence, I will use the PAYGo notation throughout the paper. 


\subsection{Individual Behavior}

Individuals maximize their expected utility (1) subject to their budget constraints. The main complications are potential imperfections in the market for private annuities.

When working, individuals earn an after-tax wage income $w_{t} \cdot\left(1-\theta_{t}\right)$ and possibly receive accidental bequests $Q^{1}$ (defined below). Denoting savings by $s_{t}$, the first period budget equation is

$$
c^{1} t=w_{t} \cdot\left(1-\theta_{t}\right)+Q^{1}-s_{t}
$$

If fair annuities exist, they offer a return $\mathrm{R}^{\mathrm{k}+1} \mu_{2 t+1}$, which is above the return on non-annuitized savings. ${ }^{14}$ Hence, all savings should be annuitized. Empirically, private annuities are so costly, however, that the bulk of private savings is not annuitized (Congressional Budget Office 1998).

To gauge the significance of this apparent market imperfection, first consider the case with fair annuities. If all assets are annuitized, surviving retirees will spend their private resources $\mathrm{R}_{t+1} / \mu_{2 t+1} \cdot \mathrm{s}_{t}$ at the rate $1 / \phi_{t+1}$, and there are no bequests. Retirement consumption (including receipts from social security) is then

$$
c^{2} t+1=\frac{R^{s}+1}{\mu_{2 t+1} \cdot \phi_{t+1}} \cdot s_{t}+\beta_{t} \cdot w_{t+1} \text {, }
$$

and savings are determined by the individual optimality condition

$$
\begin{aligned}
\rho_{1}\left(b_{t}\right) \cdot\left(c^{1} t\right)^{-\eta} & =\rho_{2} \cdot E_{t}\left[\phi_{t+1} \cdot I_{2 t+1}\right] \cdot E_{t}\left[\frac{R^{S_{t+1}}}{\mu_{2 t+1} \cdot \phi_{t+1}} \cdot\left(c^{2} t+1\right)^{-\eta}\right] \\
& =\rho_{2} \cdot E_{t}\left[R^{k}{ }_{t+1} \cdot\left(c^{2} t+1\right)^{-\eta}\right] .
\end{aligned}
$$

Note that mortality cancels out in (7a). Also, all individual and policy constraints depend on the length of life and on the survival rate only through their product $\phi_{t} \cdot \mu_{2 t}$. Hence, under the assumption of perfect

14 One may either assume that individual annuity payoffs are indexed to the ex-post

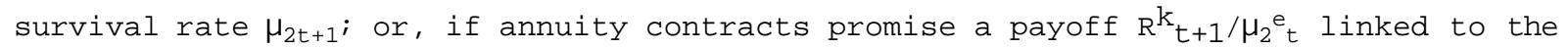
expected survival rate, one may note that annuity firms are owned, like all other firms, by the old, so that the annuity firms' aggregate profit $R^{k}{ }_{t+1}-\mu_{2 t} \cdot R^{k}{ }_{t+1} / \mu_{2} e_{t}$ accrues to the old. In either case, the old bear the risk of unexpected mortality changes. 
annuities, survival uncertainty $\mu_{2 t}$ can be subsumed into $\phi_{t}$ and does not have to examined separately.

In contrast, if annuities do not exist, those who die at the start of their retirement period must leave accidental bequests. On aggregate, bequests of

$$
R_{t+1}^{k} \cdot s_{t} \cdot\left(1-\mu_{2 t+1}\right) \cdot N_{t}^{W_{t}}=Q^{1} t+1 \cdot N_{t+1}^{W_{t}}+Q^{2}{ }_{t+1} \cdot N^{R_{t+1}}
$$

accrue either to workers (the next generation, $\mathrm{Q}^{1}+1$ ) or to other retirees (the same generation, $\left.Q^{2} t+1\right)$.

The surviving retirees will spend their private resources $R_{t+1} \cdot s_{t}$ at the rate $1 / \phi_{t+1}$. Including bequests and social security, retirement consumption is

$$
c^{2} t+1=\frac{R^{k}{ }_{t+1}}{\phi_{t+1}} \cdot s_{t}+\frac{Q^{2} t+1}{\phi_{t+1}}+\beta_{t} \cdot w_{t+1} \text {. }
$$

Savings are determined by the first order condition

$$
\begin{aligned}
\rho_{1}\left(b_{t}\right) \cdot\left(c^{1} t\right)^{-\eta} & =\rho_{2} \cdot E_{t}\left[\phi_{t+1} \cdot I_{2 t+1}\right] \cdot E_{t}\left[\frac{R^{S} t+1}{\phi_{t+1}} \cdot\left(c^{2} t+1\right)-\eta\right] \\
& =\rho_{2} \cdot \mu_{2} e_{t} \cdot E_{t}\left[R^{k}{ }_{t+1} \cdot\left(c^{2} t+1\right)^{-\eta}\right] .
\end{aligned}
$$

Savings decisions now involve the probability of survival, $\mu_{2} e$, and they are distorted because individuals do not value bequests. Moreover, accidental bequests affect the distribution of resources across cohorts to the extent that they go to the young (if $Q^{1}>0$ ).15

Despite this multitude of effects, annuities turn out to be relatively unimportant except for studying time-varying survival probabilities per se (see Section 4). Intuitively, savings distortions $\left(\mu_{2} e_{t}<1\right)$ affect the level of economic activity but they leave the propagation of other shocks and their impact on the different cohorts

15 If all bequests go to the old, missing annuities have only an incentive effect but no redistributional effect, because (6b) would then imply that the retirement income

$$
\frac{R^{k}{ }_{t+1}}{\phi_{t+1}} \cdot s_{t}+\frac{Q^{2} t+1}{\phi_{t+1}}=\frac{R^{S} t+1}{\mu_{2 t+1} \cdot \phi_{t+1}} \cdot s_{t}
$$

is the same as with annuities. 
largely unchanged. And bequests $\left(Q_{1}>0\right)$ give the young some exposure to shocks affecting capital income, but the impact is proportional to the size of such bequests relative to wage income, which is likely small.

Because of these complications and the fact that annuitized survival risk is economically equivalent to length-of-life risk, I will abstract from old-age survival risk for much of the analysis and instead focus on length-of-life uncertainty (setting $\mu_{2 t} \equiv \mu_{2}{ }_{t} \equiv 1$ ). Since shocks to survival uncertainty with fair annuities can be subsumed into $\phi_{t}$, the $\phi_{t}-$ shocks in this analysis can be interpreted as reflecting both shocks to the length of life and "diversifiable" (through annuitization) survival uncertainty. When I explicitly add survival uncertainty later (Section 4), it will be sufficient to model the case without annuities, because annuitized survival uncertainty is already covered under $\phi_{t}$.

With either assumption about annuities, the basic dynamics are similar to the Diamond (1965) model. Each period, the young divide their wage income (and bequests, if any) between consumption and savings. Savings determine the next period's capital stock, $\mathrm{K}_{\mathrm{t}+1}=\mathrm{N}_{\mathrm{t}} \mathrm{S}_{\mathrm{t}}$, which determines the wage rate for the next young generation. Since I am not interested in issues of dynamic inefficiency, I assume that $\rho_{2} \cdot \mu_{2} e_{t} / \rho_{1}\left(b_{t}\right)$ is low enough (for all $\mu_{2} e_{t}, b_{t}$ ) that the economy is dynamically efficient.

With all the shocks and flexibly parametrized preferences, the model does not generally have a closed form solution. As in Bohn (1998a), I therefore follow the RBC and finance literature and examine log-linearized solutions--analytically derived ones, however, not numerically simulated ones. To ensure balanced growth, I assume a stationary policy rule for the replacement rate $\beta_{t}$. Without government, the model would have a Markov structure with $k_{t-1}$ and the shocks $z=\left\{b_{t}, b_{t-1}, \mu_{1 t}, \phi_{t}^{u_{t}} \phi^{e_{t}}, \phi_{t-1}^{e_{t}} \mu_{2} u_{t}\right.$, 
$\left.\mu_{2} e_{t}, \mu_{2} e_{t-1}, a_{t}\right\}$ as state variables. Adding more state variables would be uninteresting. I assume therefore that the policy rule is a function of at most these variables, so that the model with government has the same structure. ${ }^{16}$

Given the Markov structure, the log-deviation of any variable (y) from the perfect foresight path is an approximately linear function of the log-deviations of the state variables. Unless otherwise noted, let symbols without time subscript refer to steady states and hats $\left({ }^{\wedge}\right)$ denote logdeviations.17 The log-linearized law of motions for any variable y can be written as ${ }^{18}$

$$
\hat{y_{t}}=\pi_{y k} \cdot \hat{k}_{t-1}+\sum_{z \in z} \pi_{y z} \cdot \hat{z}_{t} .
$$

where $\pi_{\mathrm{yz}}$ denotes the coefficient for state variable $z$. The $\pi_{\mathrm{yz}}$ coefficients can be interpreted as elasticities of $y$ with respect to $\mathrm{z}$.

The main variables of interest are the consumption of workers and retirees and the level of capital investment. Since the young divide their labor income between consumption and savings, $c^{1} t$ and $k_{t}$ depend on all shocks affecting the wage rate, on the incentives to save $\left(R^{k}+1\right)$, and on the payroll tax. The consumption of the old depends on all shocks affecting capital income and social security benefits; see (6a,b). The resulting elasticity coefficients for various specifications of the model are listed in several tables that will be discussed in the following sections.

16 Without government, one could treat $\mathrm{n}^{\mathrm{W}}$ and $\phi_{t}$ as state variables instead of their components. The components will have different effects, however, if policy treats expected and unexpected changes differently, e.g., in the conditionally prefunded system. Hence, I treat the components of $\mathrm{n}^{\mathrm{W}}{ }_{t}$ and $\phi_{t}$ as distinct state variables throughout.

17 For example, $\hat{c}_{t}^{1}=\ln \left(c^{1} t\right)-\ln \left(c^{1}\right)$. When growth rates are involved, the " $1+"$ is suppressed for notational convenience, as in $\hat{n}_{t}^{W}=\ln \left(1+n^{W}\right)-\ln \left(1+n^{W}\right)$.

18 An intercept term could be added to reflect average "displacements" from the deterministic paths caused, e.g., by risk aversion and precautionary savings; see Bohn (1998a). But since the focus here is on fluctuations and not level variables, intercept terms are omitted. 
To illustrate the practical implications of the model, I will also provide the elasticity coefficients implied by a simple numerical example. For the example, assume a capital share of $\alpha=1 / 3$, full depreciation ( $\delta=1$, payroll taxes of $\theta=0.15$, zero population growth $(n=0)$, a steady state productivity growth factor of $1+a=1.35$ (1\% annual growth for a 30-year generational period), and an elasticity of substitution of $1 / \eta=1 / 3$. The effective retirement period--length times probability--is $\lambda \cdot \mu_{2}=1 / 2 \quad($ where $\lambda=1 / 2$ and $\mu_{2}=1$, except in Sec. 4) and the time preference $\rho_{2}$ is set such that in steady state workers save 25\% of their disposable income.19

\section{The Risk-Sharing Properties of Alternative systems}

This section examines the positive effects of demographic shocks on the fortunes of different cohorts. The main sources of demographic uncertainty are shocks to the workforce and shocks to the number of retirees. For this section, I abstract from shocks that would trigger accidental bequests (setting $\mu_{2 t} \equiv \mu_{2}{ }^{e} \equiv 1$ ) and assume that all variations in old-age mortality are either changes in the known length of life or annuitized.

\subsection{Defined Benefits}

To start, consider an economy with constant social security benefits (DB). It will provide a benchmark for studying variable benefits below. Table 1 summarizes the log-linearized equilibrium responses of workers and retirees to various shocks.

19 The example is motivated by the calibrated OG model in Bohn (1998c); see there for a discussion of calibration issues. The assumed full depreciation is a convenient simplification, but it implies a caveat: Setting $\delta=1$ reduces the autocorrelation of capital $\left(\pi_{\mathrm{kk}}\right)$ and therefore understates the propagation of shocks. This is acceptablehere, because the analysis focuses on the impact effects. Setting $\delta=1$ also reduce the level of $\mathrm{R}^{\mathrm{k}}$, which $\mathrm{I}$ offset by raising $\rho_{2}$ enough that the savings rate roughly matches the empirical investment share in GDP. This is why I calibrate savings and not the time preference. 
First, consider an unanticipated shock to the number of workers $\left(\hat{n}_{t}=\hat{\mu}_{1 t} ;\right.$ Panel A). A large number of workers has a clear positive effect on the old $\left(\pi_{\mathrm{C} 2 \mu 1}>0\right)$ because the reduced capital-labor ratio increases the old generation's capital income. The impact on the young is in principle ambiguous. With a defined-benefit system, members of a large cohort pays less social security taxes $(\theta)$. But a large workforce also reduces the wage rate, as captured by negative $\alpha$-terms. The negative effects dominate whenever $\alpha>\theta /(1-\theta)$. For plausible capital shares (0.3-0.4), this inequality holds unless the tax rate is well over $20 \%$ If $\alpha>\theta /(1-\theta)$, workers' income, consumption, and savings decline in response to a positive shock to the workforce, whereas retiree consumption rises. This is also true in the numerical example: $\alpha=1 / 3>\theta /(1-\theta)=0.176, \pi_{\mathrm{c} 1 \mu 1}=-0.131$ and $\pi_{\mathrm{k} \mu 1}=-0.235$ are negative, and $\pi_{\mathrm{c} 2 \mu 1}=0.436$ is positive.

The main conclusion, to be reexamined below, is that for plausible parameters, large cohorts tend to be demographically disadvantaged. Conversely, being in a small cohort is beneficial. Even though small cohorts face relatively high taxes under a defined-benefit system, they also enjoy high wages and high returns on savings.

Second, consider shocks to the current birth rate bt (Table 1, Panel B). If one ignores children's expenses (setting $\gamma_{\rho}=0$ for this argument), shocks to the birth rate are like shocks to the labor force that become known one period in advance. With defined benefits, such shocks have no impact on the old $\left(\pi_{\mathrm{C} 2 \mathrm{~b}}=0\right)$. News about next period's labor force are relevant for the young, however, because they expect to be alive when the shock actually hits the retiree-worker ratio. Looking forward, they know that changes in $b_{t}$ have the same impact in period $t+1$ as the $\mu_{1 t+1-s h o c k s}$ discussed above: A high birth rate bt has a positive effect on retired 
generation $t$ workers. But provided $\alpha>\theta /(1-\theta)$, it has a negative effect on generation- $(t+1)$ workers.

The response of period-t workers is most likely an increase in current consumption and a reduction in savings. Specifically, Table 1 shows that the elasticities $\pi_{\mathrm{c} 1 \mathrm{~b}}$ and $\pi_{\mathrm{kb}}$ depend on the interaction of three effects. First, expected retirement income rises because a high future workforce reduces next period's capital-labor ratio and raises the return on current savings. This income effect is captured by the positive $\gamma_{\mathrm{c} 2 \mathrm{nw}}{ }^{-}$ term in $\pi_{\mathrm{clb}}$ and $\pi_{\mathrm{kb}}$. Second, the increased return triggers a substitution effect in the opposite direction (the $-\pi_{\mathrm{Rk}} / \eta$ term). Finally, expenses for children increases the consumption needs of working-age families (the $\gamma_{\rho}$ term with $\left.\gamma_{\rho}>0\right)$. Unless the elasticity of intertemporal substitution is high enough to offset both other effects, the net effects are higher consumption $\left(\pi_{\mathrm{c} 1 \mathrm{~b}}>0\right)$ and lower investment $\left(\pi_{\mathrm{kb}}<0\right)$. In the numerical example, these signs apply even for $\gamma_{\rho}=0: \pi_{\mathrm{c} 1 \mathrm{~b}}=0.08$ and $\pi_{\mathrm{kb}}=-0.24 .20$

Overall, a change in the birth rate triggers changes in consumption and capital investment before it actually affects the labor supply. The impact over time is traced out in Figures 1-2. For the figures, I consider a one-time $20 \%$ reduction in the birth rate $b_{t}$ applied to the elasticities of the numerical example. 21 In period $t$, retirees (generation $t-1$ ) are unaffected. Workers (generation $t$ ) realize that the next working-age cohort

20 Recall that $\gamma_{\rho} \in[0, \eta]$. For the upper bound $\gamma_{\rho}=\eta=3$, one obtains $\pi_{\mathrm{c} 1 \mathrm{~b}}=0.455$ and $\pi_{\mathrm{kb}}=-$ 1.365. Unless otherwise noted, I will use $\gamma_{\rho}=0$ for the example numbers, for simplicity and to avoid exaggerating the birth rate effects.

21 The $20 \%$ is somewhat less than both the projected increase in the retiree-worker ratio from 1990 to 2020 (the baby boom retirement) and the decline in the ratio of the age 0-29 population to the age 30-59 population between 1960 to 1990 (the baby bust). The example is indicative of the shape of the impulse-response functions in general, provided $\alpha>\theta /(1-$ $\theta)$ and $\gamma_{\mathrm{c} 2 \mathrm{nw}}+\gamma_{\rho} / \eta>\pi_{\mathrm{Rk}} / \eta$. One exception: For large $\gamma_{\rho}$, the sign of $\hat{c}^{2} t+1$ and the relative magnitude of $\hat{c}^{1} t$ and $\hat{c}^{2} t+1$ could be reversed, namely if reduced expenses for children dominate the baby boomers' behavior; but this seems unrealistic. 
will be small, which will reduce the return on savings. Assuming the negative income effect dominates the substitution effect, generation $t$ will reduce their consumption $\mathrm{C}^{1} \mathrm{t}$ and raise savings $k_{t}$. In period $t+1$, the lower return reduces generation $t^{\prime} s$ consumption despite the increased savings (see Fig.1). Generation $(t+1)^{\prime}$ s consumption rises, in contrast, because of higher wages. Wages are higher because of the low labor supply and because of the higher capital stock (see Fig.2). The increased wage outweighs the increase in tax rates. Since the capital stock rises, subsequent generations are better off, too.

Note that the increased period-t savings merely magnify the change in period-(t+1) wages. A reduction in $b_{t}$ would make the baby bust generation better off even if the preceding generation did not save more (say, if $1 / \eta$ were large enough that $\pi_{\mathrm{kb}}=0$ ). Increased savings further improve the consumption opportunities of the baby bust generation and their successors, but this savings response is not crucial. 22

In terms of the current policy debate, the analysis here suggests we are perhaps too worried about the baby bust generation and its ability to pay defined benefits to the baby boomers. Instead, the baby bust generation can look forward to a substantial growth in wages, whereas the baby boom generation may suffer because the small succeeding cohort reduces the return on capital.

The OG model produces strikingly different results than one would obtain in a partial equilibrium analysis (say, a trend extrapolation of the type used by the social security Administration). This is due to the endogenous factor prices. If one took wages and interest rates as given, a

22 For proof, recall the analysis of $\mu_{1 t}$-shocks, where anticipation effects did not arise. This point is worth noting because the prediction of higher savings is specific to the oG approach. If one assumed Ricardian bequests instead, a fertility decline would likely trigger a slight decline in savings; see Cutler et al. (1990). 
small workforce would leave retirees unaffected, it would make workers worse off because of higher taxes, and since workers would save less, it would make future generations worse off. If one accounts for factor price effects, however, the partial equilibrium results are reversed. The impact of factor price movements dominate the fiscal impact of labor force changes.

The latter finding relies, of course, on the general equilibrium properties of this particular two-period OG model. Perhaps most significantly, the factor price effects would be smaller if the elasticity of factor substitution were higher, e.g., with CES-technology. This and other robustness issues are examined in section 6.23

Third, returning to Table 1 (Panel C), consider a shock to the number of retirees, $\hat{\phi}_{t}=\hat{\phi}_{t}$. A large number of retirees directly reduces retiree consumption because the old have to spread their capital income over a longer period (or in case of annuitized savings, over more people). Capital investment and worker consumption are also reduced to the extent that an increased retiree-worker ratio triggers higher payroll taxes. Thus, defined-benefits social security helps to share the risk of shocks to the length of life across cohorts.

Fourth, consider a current shock to $\phi^{e} t$, the expected length of life ("life expectancy") in period t+1. Table 1, Panel D shows that current life-expectancy has an impact on the young, who will experience a longer life, but no impact on the old $\left(\pi_{C 2 \phi e}=0\right.$, as in the case bt shocks). Looking forward, a lagged length-of-life shock matters through its impact on the actual number of retirees $\left(\phi_{t+1}\right)$, like the unexpected shock $\phi^{u_{t+1}}$. The young

23 To avoid clutter, I proceed with the basic model and defer all extensions and empirical issues. 
have an incentive to increase their savings and to reduce their current consumption $\left(\pi_{\mathrm{k} \phi e}>0, \pi_{\mathrm{c} 1 \phi e^{<0}}\right) .24$ This risk is not shared with the old.

Finally, consider the capital and productivity coefficients in Table 1, Panel E. Not surprisingly, a high capital-labor ratio raises capital and labor incomes, hence consumption and savings. This makes $k_{t}$ autocorrelated and propagates shocks. Productivity shocks have a negative impact on consumption and capital when scaled by productivity $\left(c^{1} t / A_{t}, c^{2} / A_{t}, a n d ~ k_{t}\right)$ because a rise in $A_{t}$ raises output less than one-for-one. In level terms, however, a positive shocks to at raises consumption $\left(c^{1} t, c^{2}\right)$ and the percapita savings $\mathrm{k}_{\mathrm{t}} \cdot \mathrm{A}_{\mathrm{t}}$.

Since a shock to productivity affects the capital-labor ratio like an unexpected shock to the workforce, one may wonder to what extent the $\mu_{1 t}$ and at shocks have similar effects. If social security is small $(\theta \approx 0)$, positive shocks to $a_{t}$ and $\mu_{1 t}$ will indeed increase retiree consumption by the same amount $\left(1+\pi_{\mathrm{C} 2 \mathrm{a}}=\pi_{\mathrm{C} 2 \mu 1}\right.$ for $\left.\theta=0\right)$. They have very different effects on current workers, however, since an increase in $A_{t}$ raises the wage while a rise in $\mathrm{N}^{\mathrm{W}}$ reduces the wage rate. For $\theta>0, a_{t}$ and $\mu_{1 t}$ shocks also have different effects on retirees because they have different distributional effects through social security.

\subsection{Variable Benefits}

The analysis so far has shown that most shocks affect different generations differently or even in opposite directions. This suggests some scope for improved risk sharing. The section examines how the allocation of risk is modified by policies with variable social security benefits.

24 The overall effects of increased life-expectancy over time could be traced out as in Table 2, but the results would just confirm the increase in savings and the reduction in per-capita consumption. 
Alternative policies are defined by their elasticity coefficients $\pi_{\beta z}$, i.e., by how the replacement rate $\beta$ responds to different shocks. Table 2 shows how the equilibrium dynamics of consumption and capital investment are affected in general by alternative $\pi_{\beta z}$-values. To help interpret the general results, Table 3 displays the elasticity coefficients corresponding to the four main policy alternatives--the DB, DC, privatized, and conditionally prefunded social security systems--in the numerical example. 25 In general, the elasticity formulas in Table 2 include the same elements as the corresponding formulas in Table 1, but there are additional terms that capture the effects of a changing replacement rate. The policy coefficients are generally weighted by the size of government transfers relative to the cohort's income, which is $\gamma_{c 2} \beta$ for retirees and $-\theta /(1-\theta)$ for workers. For workers, the impact is then divided between consumption and savings in proportions $\Delta_{\mathrm{C}}: \Delta_{\mathrm{k}}$.

Any policy that reduces prospective benefits when the birth rate declines and/or the life-expectancy rises is characterized by policy coefficients $\pi_{\beta b 1}>0$ and/or $\pi_{\beta \phi e 1}<0$. A pure defined-contributions system would have $\pi_{\beta \mu 1}=\pi_{\mathrm{b} 1}=1$ and $\pi_{\beta \phi u}=\pi_{\beta \phi e 1}=-1$. Since U.S. retirees have generally been protected against unexpected shocks, the U.S. system seems to maintain defined benefits with respect to unexpected changes $\left(\pi_{\beta \phi u}=\pi_{\beta \mu 1}=0\right)$, but allows benefits to change after a phase-in, suggesting $\pi_{\beta \mathrm{b} 1} \neq 0$ and $\pi_{\beta \phi e 1} \neq 0$. The tax increases and the trust fund buildup since 1983 suggests that the U.S. system is somewhere between a DC and a DB system with respect to anticipated changes, i.e., $0<\pi_{\beta b 1}<1$ and $0>\pi_{\beta \phi e 1}>-1$. These stylized facts are captured by the conditionally prefunded system ("Prefunded" in Table 3).

25 The numerical example is broadly indicative of how the elasticities compare in general. 
For the numerical illustration of this system, I assume $\pi_{\beta \mathrm{b} 1}=0.5$ and $\pi_{\beta \phi e 1}=-$ 0.5

In case of shocks to the workforce, Table 3 (Panel A) shows that defined contributions and privatized systems magnify the negative exposure of workers to such shocks as compared to the DB case. They also magnify the positive exposure of retirees. Table 2 (Panel A) shows that this is true in general, whenever $\pi_{\beta \mu 1}>0$ and $\pi_{\beta \mathrm{b} 1}>0$. In addition, $\pi_{\beta \mathrm{b} 1}>0$ increases workers instantaneous negative response to birth rate shocks $\left(\pi_{\mathrm{kb}}<0\right.$ rises in absolute value; see Table 2, Panel B). By making the capital-labor ratio more volatile, $\pi_{\beta b 1}>0$ also exposes future generations to more risk. These observations reinforce the insights from Table 1: Large cohorts are already demographically disadvantaged at fixed benefits (DB). Hence, a policy of giving them reduced benefits in order to stabilize tax rates is counterproductive. 26

In case of shocks to the current length of life, a system of defined contributions leaves the old more exposed and allocates less risk to the young than a DB system: In Table 2 (Panel C), if $\pi_{\beta \phi e 1}<0$ and/or $\pi_{\beta \phi u}<0$, then $\pi_{\mathrm{c} 1 \phi u}, \pi_{\mathrm{c} 1 \phi e 1}, \pi_{\mathrm{k} \phi \mathrm{u}}$, and $\pi_{\mathrm{k} \phi e 1}$ are all lower in absolute value, whereas $\pi_{\mathrm{c} 2 \phi u}$ and $\pi_{\text {c2申e1 }}$ are increased. With a DC system, length-of-life risk falls entirely on the old. The policy coefficient $\pi_{\beta \phi e 1}$ also influences how period-t voters response to news about changes in the future length of life $\left(\phi^{e}{ }_{t}\right.$-shocks; see Table 2, Panel D). If workers anticipate reduced future benefits, they save more $\left(\pi_{\beta \phi e 1}<0\right.$ raises $\left.\pi_{k \phi e}\right)$ and consume less $\left(\pi_{\beta \phi e 1}<0\right.$ reduces $\left.\pi_{\mathrm{c} 1 \phi e}\right)$.

Table 2 provides several additional insights. First, the government can influence the propagation of shocks through the capital-labor ratio

26 This verdict may raise questions about the welfare criterion. This will be addressed below. 
$\left(\pi_{k k}\right)$ by making benefits a function of $k_{t-1}$ (setting $\pi_{\beta k} \neq 0$; see Panel E). Second, the government can influence the incidence of productivity shocks by varying $\pi_{\beta a}$. Third, note that for $\pi_{\beta b}=\pi_{\beta \phi e}=0$, only the workers bear the risk of "bad" news about birth rates and life-expectancy (see Panels B and D). By setting $\pi_{\beta b}, \pi_{\beta \phi e^{\neq}} 0$ the government could spread such risks over young and old. This is not done under any of the policies discussed above.

Overall, Table 3 provides a comparison of the main policy alternatives. Under DC and private savings systems, all length-of-life risk is carried by the old and none by the young. The DB and prefunded systems shift some of these risks to the young. Under DC and private savings systems, birth rate uncertainty and other shocks to the workforce have a positive impact on the old but a negative impact on the young. This negative comovement of worker and retiree consumption is reduced by the DB and prefunded systems, but provided $\theta /(1-\theta)<\alpha$, it is not eliminated.

\section{Missing Annuities and Accidental Bequest}

This section examines the ramifications of missing annuities and accidental bequests. Without annuities, some shocks to old-age survival lead to accidental bequests $\left(\mu_{2}\right.$-shocks). In addition, the existence of accidental bequests affects the propagation of the shocks examined previously.

The macroeconomic dynamics of the log-linearized model without annuities are summarized in Table 4. Recall that in the basic model, $\phi-$ shocks reduced retiree consumption while affecting worker consumption only through a change in taxes. In contrast, if savings are not annuitized, fewer unexpected deaths (higher $\mu_{2} u_{t}$ or $\mu_{2}{ }^{e}-1$ ) have a direct negative effect on the young because of reduced bequests, while the old are affected only through changes in benefits (see Panel A). If benefits are held constant, the consumption of the young is further reduced because of higher taxes. 
Table 4, Panel A, also provides numerical values for the limiting case of $q \approx 0$ and $a$ DB social security system. For $q \approx 0$ and DB, survival shocks affect the worker exactly like a length of live shock (see Table 1, Panel C). The key difference is that retirees are unaffected. Hence, for dealing with $\mu_{2}$-type shocks, a movement towards defined contributions or privatization looks much more promising than for $\phi$-type shocks.

Table 4, Panel B, illustrates how an increase in the expected future probability of survival $\left(\mu_{2}{ }^{e}\right)$ increases workers' incentives to save. Panels C-G show how accidental bequests modify the other policy coefficients as compared to Table 2. The modifications are proportional the ratio of accidental bequests to bequests plus wage income (q). If this ratio is small, as one might expect in practice, the previous results remain virtually unchanged. For this reason, no new illustrative values are provided.

\section{Efficient Risk Sharing}

If there is scope for risk-sharing, what exactly should be done? This section derives a simple efficiency benchmark and explores its policy implications. In general, the set of efficient (ex-ante Pareto-optimal) allocations can be obtained by maximizing a welfare function

$$
W=E\left\{\sum_{t=-1}^{\infty} \Omega_{t-1} \cdot \mathrm{N}_{t-1} \cdot \mathrm{U}_{\mathrm{t}}\right\}
$$

with welfare weights $\Omega_{t-1}>0$, subject to the feasibility constraints (1)-(4) and given $\mathrm{K}_{0} \cdot{ }^{27}$ The efficiency conditions are

27 The definition of efficiency is non-trivial because one might instead consider a welfare function with state-contingent weights. In a model without childhood period, Peled (1982) has shown that the market allocation without government is Pareto-efficient if one interprets generation-t individuals born in different states of nature as different individuals and applies state-contingent weights. With a childhood period, the market allocation is inefficient even with state-contingentweights. Moreover, Peled'sdefinition is too weak here, because it would rationalize any shift of risk from current to unborn generations as efficient (under some state-contingent welfare weights) and therefore make the policy analysis vacuous. Readers who object on philosophical grounds to the notion of 


$$
\begin{aligned}
& \Lambda_{t} \cdot \mathrm{N}^{\mathrm{W}_{t}}=\Omega_{\mathrm{t}-1} \cdot \mathrm{N}_{\mathrm{t}-1} \cdot \mu_{1 \mathrm{t}} \cdot \frac{\mathrm{dE}_{\mathrm{t}} \mathrm{U}_{\mathrm{t}}}{\mathrm{dc}^{1} \mathrm{t}}, \\
& \Lambda_{t} \cdot \mathrm{N}_{t}=\Omega_{t-2} \cdot \mathrm{N}_{\mathrm{t}-2} \cdot \mu_{1 t-1} \cdot \mu_{2 t} \cdot \frac{\mathrm{dU}_{\mathrm{t}-1}}{\mathrm{dc}^{2} t}, \\
& \text { and } \quad \Lambda_{t}=E_{t}\left[\Lambda_{t+1} \cdot R^{k}{ }_{t+1}\right] \text {, }
\end{aligned}
$$

where $\Lambda_{t}$ is the shadow value of the resource constraint (4). Equivalently,

$$
\begin{aligned}
& \rho_{1} \cdot\left(c^{1} t\right)^{-\eta}=E_{t}\left[R_{t+1}^{k} \cdot \rho_{2} \cdot\left(c^{2} t+1\right)^{-\eta}\right], \\
& \rho_{1}\left(b_{t}\right) \cdot\left(c^{1}\right)^{-\eta}=\frac{\Omega_{t-2}}{\Omega_{t-1}} \cdot \rho_{2} \cdot\left(c^{2}\right)^{-\eta}
\end{aligned}
$$

define the efficient linkages of consumption over time and across generations. Note that equation (12a) is identical to the individual optimality condition (7a) for generation $t^{\prime}$ s savings with annuities. The fundamentally new equation is (12b). It links period-t worker and retiree consumption and it depends only on population growth and on the welfare weights.

For risk sharing issues, it is again useful to distinguish the economy's perfect foresight path (obtained by setting all shocks to zero) from the stochastic fluctuation around this path. For the log-deviations from the perfect foresight path, equation (12b) implies

$$
\hat{c}_{t}^{1}=\hat{c}^{2} t+\gamma_{\rho} / \eta \cdot \hat{b}_{t}
$$

This is a strong restriction on the co-movements of worker and retiree consumption: In any efficient allocation, both generations consumption must respond in equal proportions to ALL unexpected disturbances, except to the extent that parents' consumption needs vary with the number of children $\left(b_{t}\right)$

The key underlying assumption is CRRA utility, which assigns an equal relative risk aversion to both generations. For utility functions with age-

unborn individuals may instead interpret the state-independent weights as an assumption of "distributional neutrality," meaning that we are looking for allocations in which the government does not arbitrarily value individuals born in one state of nature more highly than individuals with equal consumption born in another state. 
dependent risk aversion, Bohn (1998a) has shown that macroeconomic risks would be shared in inverse proportion to the relative risk aversions. The same would be true here, but age-dependent risk-aversion would unnecessarily complicate the analysis. Age-dependent risk aversion would not, in any case, overturn the basic point that all risks should be shared across generations.

In addition to sharing risks between living generations, government policy has the ability to re-allocate risks between current and future generation by imposing history-dependent policies. This is generally necessary to obtain a first-best allocation and it typically involves making policies a function of the capital-labor ratio $k_{t-1}$ (see Bohn 1998 a). For the analysis here, making $\beta_{t}$ a function of $k_{t-1}$ would be a distraction. Instead, I focus on the necessary efficiency condition (13) when comparing alternative social security systems. Its key implication for the elasticity coefficients is that for all shocks, the consumption coefficients for workers and retirees should be equal. The only exception are the $b_{t}{ }^{-}$ coefficients to the extent that expenses for children matter.

Applied to the different demographic shocks, the optimality condition (13) yields a set of optimal policy coefficients $\pi^{\star} \beta$ that are displayed in Table 5 .

For shocks to the actual workforce $\left(\mu_{1 t}, b_{t-1}\right)$, the optimal policy coefficients $\pi^{\star} \beta \mu 1$ and $\pi^{\star} \beta$ b1 are clearly negative for reasonable $\alpha$ and $\theta$ values. This is true not only for $\alpha>\theta /(1-\theta)$, but even for higher $\theta$ values, provided

$$
\alpha+\left(\gamma_{\mathrm{C} 2 \mathrm{nw}}+\Delta_{\mathrm{C}} \cdot \mathrm{q} \cdot \pi_{\mathrm{Rk}}\right) / \Delta_{\mathrm{C}}^{*}>\theta /(1-\theta)
$$

Since the bracketed term is positive, this strengthens the previous observation that large cohorts are worse off than small cohorts even with 
PAYGO-DB. Intuitively, the bracketed term captures the impact of interest rate movements that favor small cohorts. In the numerical example, $\pi^{\star} \beta \mu 1=\pi^{\star} \beta \mathrm{b} 1=-1.5$ are far below zero. Applied to the current baby boom/bust situation, this implies that benefits should be increased as the baby boom cohort retires. This is contrary to most proposals in the current policy debate.

The optimal response to a current birth rate shock (bt) is somewhat more complicated. In the formula for $\pi^{\star} \beta \mathrm{b}$ in Table 5 , if $\gamma_{\mathrm{c} 2 \mathrm{nw}}-\pi_{\mathrm{Rk}} / \eta>0$, the positive income effect of higher future returns on capital exceeds the substitution effect and tends to increase worker consumption. Efficiency would call for this "windfall" to be shared with the old through higher benefits. On the other hand, if $\pi_{\beta b 1}=\pi^{\star} \beta_{b 1}<0$ takes its optimal negative value, worker income is reduced, which would call for a benefit reduction. The $\gamma_{\rho}$ term reflects the cost of children. If workers have higher expenses for more children, a reduction in social security benefits would be efficient. The sum of these effects has an ambiguous sign.

In the numerical example, $\pi^{\star} \beta b=0.212$ is positive if $\pi_{\beta b 1}=0$ (e.g., with $\mathrm{DB}), \pi^{\star} \beta \mathrm{b}=0.441$ is even higher if $\pi_{\beta \mathrm{b} 1}=1$ (e.g., with $\left.\mathrm{DC}\right)$, but $\pi^{\star} \beta \mathrm{b}=-0.131$ takes a negative value if $\pi_{\beta b 1}=\pi^{\star} \beta \mathrm{b} 1=-1.5$ is set optimally. Intuitively, the lagged policy response $\pi_{\beta b 1}$ matters because workers' period-t decisions depend on how they expect to be treated by the government as retirees. If a rise in the birth rate signals no change in future benefits (with DB) or increased retirement benefits (with DC), workers expect to be very well off as retirees and increase their current consumption. The optimality condition (13) implies that the good fortune should be shared with current retirees. A reduced birth rate--the current U.S. scenario--would then call for an immediate benefit cut. If future benefits are set optimally, on the 
other hand, a rise in the birth rate signals a benefit cut, and workers will reduce their consumption. Then the optimal current policy response has the reverse sign.

In any case, efficiency calls for current retirees to share the impact of birth rate shocks. And unless the baby boomers are confident that future policy-makers will follow the advice of this paper (that $\pi^{\star} \beta \mathrm{b} 1<0$ ) rather than the thrust of the current social security debate (moving towards $\left.\pi_{\beta \mathrm{b} 1}>0\right)$, they are well advised to reduce current consumption and to save more.

Next, consider length-of-life shocks without impact on accidental bequests $\left(\phi^{u_{t}}, \phi_{t-1}^{e_{t}}\right)$. Recall that in a DB system both generations' consumption falls in response to an increase in the length of life. The optimal policy response therefore depends on the relative impact. For reasonably small $\theta$ values, the old are more affected than the young (recall Table 1, Panel $\mathrm{C}$ ). Then the benefits to the old should be increased in response to longer life expectancy, i.e., $\pi^{\star} \beta \phi u=\pi^{\star}{ }_{\phi e 1}>0$. In the numerical example, $\pi^{\star} \beta \phi u=\pi^{\star}{ }_{\phi e 1}=1.647$ is indeed far above zero.

Without annuities, the results are different. With defined benefits, only the young would bear the cost of survival shocks $\left(\mu_{2} u_{t}, \mu_{2}^{e} t-1\right)$. A benefit reduction, $\pi^{\star} \beta \mu 2 u^{*} \pi^{\star} \mu 2 e 1<0$, is therefore efficient. Provided $\mu_{2}$ and $q$ are small enough that $\gamma_{c 2} \beta>q \cdot \mu_{2} /\left(1-\mu_{2}\right) \cdot \theta /(1-\theta)$, the optimal policy is in the range $-1<\pi^{\star} \beta \mu 2 u=\pi^{\star} \mu 2 e 1<0$, so that efficiency calls at most for a partial movement to DC. In the numerical example, one finds $\pi^{\star} \beta \mu 2 u^{*}=\pi^{\star} \mu 2 e 1=-$ 0.389 .

Overall, if one asks the broad question of how social security should respond to lower mortality per se, the right answer is that it depends on the type of shock. If the type is unknown, the large positive $\pi^{\star}-$ 
coefficient for $\phi$-shocks in the numerical example as compared to the small negative coefficient for $\mu_{2}$-shocks suggests that there is no strong case for a benefit reduction.

Finally, for shocks to current life-expectancy $\left(\phi^{e} t\right.$ and $\left.\mu_{2} e_{t}\right)$, recall that both shocks reduce the consumption of the young without directly affecting the old (See Table 1, Panel D; Table 4, Panel B). Hence, the optimal policy response is to reduce the benefits to the old, $\pi^{\star} \beta \phi e^{<0}$ and $\pi^{\star} \beta \mu 2 e^{<0.28}$ Intuitively, increased life-expectancy requires resources in the future, so that the young need to save more. For the old to share the burden, current social security benefits should be reduced immediately. This conclusion applies regardless of the state of annuity markets.

In the current reform debate, many proposals call for a reduction in benefits as mortality declines, e.g., by increasing the retirement age. The analysis here suggests that the efficiency of such benefit cuts depends importantly on their timing. Cuts are efficient if they are imposed quickly (at time $\left.t, \pi^{\star} \beta \phi e^{<0}\right)$, but not if they are imposed so late that they fall on the longer-lived cohort itself (at time $\left.t+1, \pi^{\star} \beta \phi e 1>0\right)$. None of the systems discussed in the current reform debate is efficient in this sense, nor is the current policy debate moving in the direction of cutting benefits to current retirees.

\section{Extensions and Empirical Issues}

The magnitude of factor price movements in response to demographic shocks was a key issue in the analysis above. Is the model consistent with the

28 In the numerical example, one finds $\pi^{\star} \beta \phi e^{=-0.76}$ if $\pi_{\beta \phi e 1}=0$ and $\pi^{\star} \beta \phi e^{=-1.14}$ if $\pi_{\beta \phi e 1}=\pi^{\star} \beta \phi e 1=1.647$. Without annuities, $\pi^{\star} \beta \mu 2 e^{=-0.057}$ if $\pi \beta \mu 2 e 1=0$ and $\pi^{\star} \beta \mu 2 e^{=-0.146}$ if $\pi_{\beta \mu 2 e 1}=\pi^{\star} \beta \mu 2 e 1=-0.389$. The $\pi_{\beta \phi e 1}$ and $\pi_{\beta \mu 2 e 1}$ coefficients matter because workers take the expected future policy response to any shock to life-expectancy into account when they decide about their consumption (as explained in the case of $b_{t}$ shocks). 
empirical evidence? Are there natural extensions of the model that would yield different results? To address these concerns, this section comments on the empirical evidence and on some extensions of the model.

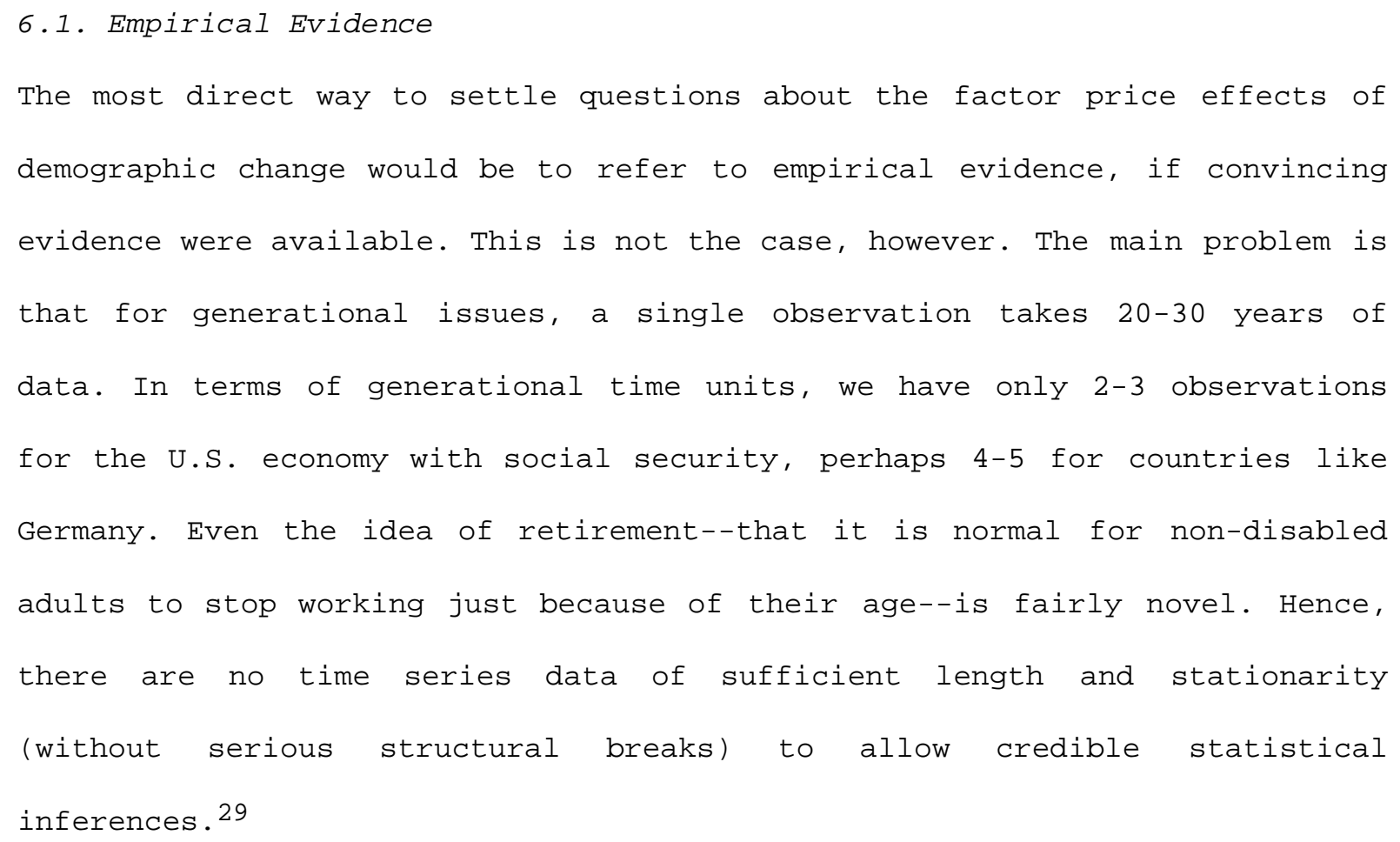

29 Poterba (1998) makes similar arguments.

30 There is some debate about the strength of this relation; see Barro and Sala-i-Martin (1995) and Temple (1998). While cross-sectional evidence is attractive to circumvent the lack of multi-generation time series, it also raises new concerns about causality and control variables. Hence, the evidence should be interpreted cautiously. 
Easterlin, 1987; Murphy and Welch, 1992; Macunovich, 1998).31 Easterlin and Macunovich focus almost exclusively on demographics and argue that the effects are large. Welch (1979) and Berger (1985) find significant negative effects of cohort size on cohort wages, though they disagree about the persistence over a worker's career. Murphy and Welch (1992) argue that demographic variables are only a minor determinant of relative wages, but even they find non-trivial cohort effects.

To be conservative, I will focus on Welch (1979) and Murphy-Welch (1992). Welch's (1979) elasticity estimates for the "persistent" impact of cohort-size (narrowly defined as a 5-year age window) on annual wage income are around -0.20 , with some variation across education categories. Murphy and Welch's simulations (1992, p.324) imply that a 20\% increase in the number of young workers reduces their wages by 6-15\%, suggesting an elasticity of relative wages in the range -0.30 to -0.75 .

For comparison, the OG model assumes an elasticity of wages with respect to the aggregate workforce of $-\alpha$ or about -0.33 , a value well within the range of elasticities above. Moreover, if capital-owners have some ability to substitute labor across narrowly defined age cohorts, the elasticity of wages with respect to the aggregate workforce should be at least as high as the relative-supply elasticities. Thus, the assumptions of the OG model are not inconsistent with the labor economics evidence.

Finally, I should comment on the relation between demographics and the return on capital. The recent review by Poterba (1998) finds little evidence of a systematic relation. Poterba suggests that this may be due to the small number of generational degrees of freedom. Theoretical considerations suggest an additional rationalization: If old capital is a

31 This literature should also be interpreted cautiously. Despite the richness of panel data, the data provide aggregate information about only 1-2 generations. 
large share of the total return (if $(1-\delta) / \mathrm{R}^{\mathrm{k}}$ is near one), then the elasticity of $\mathrm{R}^{\mathrm{k}}$ with respect to the capital-labor ratio is small and may be difficult to detect empirically.32 Thus, the inability to find an empirical link between demographics and stock returns is not inconsistent with the model.

\subsection{CES-Production}

From a theoretical perspective, the magnitude of factor price movements depends importantly on the elasticity of factor substitution. By assuming Cobb-Douglas technology, the analysis above implicitly assumes a unit elasticity. An elasticity of factor substitution above 1.0 will imply smaller factor price changes than with Cobb-Douglas, and hence, a different allocation of risk. To examine the importance of this issue, this section replaces Cobb-Douglas by CES production.

For this section only, let output be produced with a CES-technology, $Y_{t}=\left[\alpha_{\varphi} \cdot K_{t}{ }^{1 /(1-\varphi)}+\left(1-\alpha_{\varphi}\right) \cdot\left(A_{t} \cdot N^{W}\right)^{1 /(1-\varphi)}\right]^{1-\varphi}$, where $\varphi$ is the elasticity of substitution between capital and labor, and $0<\alpha_{\varphi}<1$. Cobb-Douglas technology is covered as the limiting case $\varphi \rightarrow 1$. Leaving all other assumptions unchanged (and setting $\mu_{2}=1$ for simplicity), the economy is still a Markov process with unchanged state variables, but with modified dynamics.

Table 6 summarizes the consumption and investment dynamics with CESproduction. The key difference to Table 2 is that the elasticities of the wage and the return on capital with respect to movements in the capitallabor ratio are scaled down by a factor $\varphi .33$ In the young generation's

32 For annual data, Bohn $(1998 \mathrm{C})$ suggest $(1-\delta) / \mathrm{R}^{\mathrm{k}} \approx 85 \%$ so that $\pi_{\mathrm{Rk}} \approx 0.10$. (In the numerical example, the role of $\delta$ was ignored for simplicity.) The same argument suggests that the transmission of demographics to the stock market may occur in part through variations in the value of old capital (say, if $1-\delta$ is stochastic), and not only through the production function. This is an open question left for future research.

33 A variable factor share also complicates the calculation of the old generation's income and it alters the propagation of shocks. 
response to birth rate shocks, $\alpha$ is replaced by $\alpha / \varphi$, and in $\pi_{\mathrm{Rk}},(1-\alpha) / \varphi$ replaces $(1-\alpha)$, where $\alpha$ is now the steady state capital share.

The impact of birth rate and other workforce shocks on the fortunes of differently-sized cohorts now depends on the relation between $\alpha / \varphi$ to $\theta /(1-\theta)$. Given a defined-benefit social security system, unexpected shocks to the labor force are beneficial to a small cohort if and only if

$$
\alpha / \varphi>\theta /(1-\theta)
$$

For elasticity values $\varphi<1$, this inequality is satisfied even more clearly than for Cobb-Douglas. To overturn (15), one would have to argue that the capital-labor elasticity is far above one. In the numerical example with $\theta=15 \%$ and $\alpha=1 / 3$, one would need an elasticity above 1.88 . The empirical production literature suggests, however, that the elasticity is probably below rather than above one (e.g., Lucas 1969). Hence, it is difficult to question (15) on the basis of production theory.

Outside the model, one might think of international capital and labor movements as factors that could weaken the link between U.S. factor supplies and factor prices. If one interprets $1 / \varphi$ more broadly as parametrizing the magnitude of factor price movements in response to demographic change, increased openness might be interpreted as an increased $\varphi$-value. Feldstein and Horioka (1980) have documented, however, that international savings-investment linkages have historically been unimportant, justifying a closed economy analysis. 34

Thus, concerns that the Cobb-Douglas assumption might over-emphasize factor price movements are probably unwarranted. Based on production

34 Also, openness would presumably matter most if demographic change abroad were orthogonal to the U.S. But many other countries are undergoing a similar demographic transition as the U.S. 
function estimates, Cobb-Douglas might even understate the factor price movements, which would give small cohorts an even better starting position.

\subsection{Elastic Labor Supply}

Elastic labor supply is another consideration that could change the impact of demographics. The most serious concern is that if small cohorts supplied more labor, birth rate changes would have a reduced impact on the capitallabor ratio and on factor prices.

A complete model with endogenous labor supply would complicate the analysis too much to fit into this already long paper. Some results can be obtained quite easily, however. Assume DB social security and Cobb-Douglas technology. Then at any level of per-capita labor supply, a large cohort will face a lower after-tax wage than a smaller cohort if and only if the inequality $\alpha>\theta /(1-\theta)$ is satisfied. Thus, large cohorts face a relatively reduced opportunity set. This shows that labor supply considerations cannot overturn the basic qualitative finding that large cohorts are demographically disadvantaged for $\alpha>\theta /(1-\theta)$.

Quantitatively, the implications of a variable labor supply depend on a tradeoff between income and substitution effects. The negative income effect of a low wage may induce a large cohort to work more, while the negative substitution effect would encourage taking leisure. If the substitution effect is weak, a variable labor supply might even magnify movements in the effective capital-labor ratio.

\subsection{Time-Aggregation}

Factor price changes and cohort welfare may also be affected by timeaggregation. If one used a more elaborate model of the life-cycle with multiple working-age periods, large and small cohorts might overlap in the labor force, leading to reduced fluctuations in the labor force and in the 
retiree-worker ratio. In addition, "middle-aged" workers might supply both capital and labor, which would reduce the welfare-impact of factor price changes. 35 Are such extensions likely to overturn the results obtained here? A more disaggregate approach would clearly yield different quantitative implications, but it is doubtful that these modifications will overturn any important results. To see why, first consider labor supply. Suppose one started out with, say, cohorts defined by the year of birth. Then the significance of being in a small or large birth cohort depends on the persistence of birth rate shocks and on the substitutability of wages across birth cohorts. If workers of different age are close substitutes, wage movements are small unless the aggregate labor force varies significantly. And if shocks are temporary, they would have little impact on the labor force. The baby boom/bust phenomenon suggest, however, that demographic shocks have enough persistence to matter at generational frequencies. And the labor literature (see above) suggests that substitution across cohorts is not perfect.

To sidestep any controversy about relative wage effects, assume for the sake of argument that all workers are perfect substitutes. 36 If small and large cohorts overlap in the labor force, it is true that the magnitude of wage fluctuations would be less than in a crude model that abstracts from such overlap. However, the same overlap would also reduce the fluctuations in the PAYGO tax rate, and by the same percentage. Provided $\alpha>\theta /(1-\theta)$, changes in the workforce still affect wages more than taxes. Thus, an overlap of large and small cohorts in the workforce is unlikely to affect the relative importance of fiscal versus factor price effects.

35 I would like to thank Kevin Murphy, the discussant, for raising this issue. Kevin also raised the issue of retirees receiving labor income, but $I$ doubt that this is quantitatively as significant.

36 otherwise, even changes in narrowly defined cohorts would have factor price effects. 
Second, consider the issue of middle-aged workers receiving both capital and labor income. This issue is not about the size of factor price changes but about their welfare impact. Members of a large cohort are less worse off than in the basic model, if they receive some of the high capital incomes generated by their own large cohort size. Note, however, that demographically driven changes in the return to capital were only one of several "transmission mechanisms" in the analysis above. Smaller cohorts would be better off than large ones even if the return on capital were held constant. To make large cohorts better off, the demographic effects trough the return to capital would have to outweigh the effects through the aftertax wage. Empirically, most of the gross return on aggregate capital on an annual basis is due to the value of old capital (see above). The "within-ageneration" elasticity of $\mathrm{R}^{\mathrm{k}}$ with respect to the capital-labor ratio is therefore likely small. In addition, households tend to accumulate financial assets fairly late in their careers (Poterba 1998). Hence, the receipt of capital income by worker households is unlikely to overturn the results from the basic OG model.

\section{Conclusions}

The paper examines demographic uncertainty in a neoclassical growth model with overlapping generations. I compare the allocation of risk implied by alternative social security policies to the ex-ante efficient allocation. The policy answers depend significantly on how strongly factor prices respond to demographic change. For plausible tax rates and elasticities of factor substitution, small cohorts are actually better off than large cohorts even in a defined benefits social security system. This is because small cohorts enjoy favorable wage and interest rate movements. Benefit 
cuts and/or pre-funding in response to an unexpected decline in the birth rate would be inefficient.

The efficient responses to changes in life-expectancy depend significantly on the type of change. If individuals know that the will live longer or if fair annuities are available to diversify the risk of unexpected deaths, a longer life-expectancy should trigger an increase in retirement benefits to those who live longer, but a benefit reduction to the previous cohort. Reduced benefits to those who expect to live longer are efficient only if increased old-age survival leads to reduced accidental bequests to the next generation.

Overall, the efficiency analysis yields policy conclusions that differ significantly from the proposals in the current reform debate. Notably, the efficient response to a baby boom is to increase the retirement benefits of the baby boomers, even at the cost of tax increases to the baby bust generation; and the efficient response to news about increased future life-expectancy is to cut benefits to current retirees.

With regard to birth rate shocks, I obtain conclusions that differ from the conventional wisdom, because my analysis includes endogenous factor price movements. Factor price effect are largely ignored in the current policy debate. The social security Administration, for example, makes long run projections of future wages and interest rates by extrapolating past trends. The analysis of this paper suggests that the omission of endogenous factor price movements is seriously misleading under empirically realistic parametric assumptions. 


\section{References}

Abel, Andrew, 1998, The Aggregate Effects of Including Equities in the Social Security Trust Fund, mimeo, University of Pennsylvania.

Abel, Andrew, 1999, The Social Security Trust Fund, The Riskless Interest Rate, and Capital Accumulation, Paper presented at the NBER Conference on Risk-Aspects of Investment-based Social Security Reform.

Altonji, Joseph, Fumio Hayashi, Laurence Kotlikoff, 1996, Risk Sharing between and within Families, Econometrica 64, 261-294.

Barro, Robert, and Xavier Sala-i-Martin, 1995, Economic Growth, New York: McGraw-Hill.

Berger, Mark, 1985, The Effect of Cohort Size of Earnings Growth: A Reexamination of the Evidence, Journal of Political Economy 93, 561-573. Bohn, Henning, 1997, Social Security Reform and Financial Markets, in: Steven Sass and Robert Triest (eds.), Social Security Reform: Links to Savings, Investment, and Growth, Boston: Federal Reserve Bank of Boston, $193-227$.

Bohn, Henning, 1998a, Risk Sharing in a Stochastic Overlapping Generations Economy, mimeo, University of California Santa Barbara.

Bohn, Henning, 1998b, Will Social Security and Medicare Remain Viable as the U.S. Population is Aging?", Paper presented at the CarnegieRochester Conference on Public Policy.

Bohn, Henning, 1998c, Should the Social Security Trust Fund hold Equities? An Intergenerational Welfare Analysis, mimeo, University of California Santa Barbara.

Congressional Budget Office, 1998, Social Security Privatization and the Annuities Market, Washington, D.C.: U.S. Government Printing Office.

Cutler, David, James Poterba, Louise Sheiner, and Lawrence Summers, 1990, An Aging Society: Opportunity or Challenge? Brookings Papers on Economic Activity, $1-56$.

Diamond, Peter, 1965, National Debt in a Neoclassical Growth Model, American Economic Review 55, 1126-1150.

Easterlin, Richard, 1987, Birth and Fortune: The impact of numbers of personal welfare, Chicago: University of Chicago Press, 2nd ed.

Feldstein, Martin, and C. Horioka, 1980, Domestic Savings and International Capital Flows, Economic Journal 90, 314-329. 
Lucas, Robert, 1969, Labor-Capital Substitution in U.S. Manufacturing, in Arnold Harberger and Martin Bailey (eds.), The Taxation of Income from Capital, Washington: Brookings Institution, 223-274.

Macunovich, Diane, 1998, Relative Cohort Size and Inequaliy in the United States, American Economic Review 88, 259-264.

Mankiw, Gregory, David Romer, and David Weil, 1992, A Contribution to the Empirics of Economic Growth, Quarterly Journal of Economics 107, 407437.

McHale, John, 1999, The Risk of Social Security Benefit Rule Changes: Some International Evidence, Paper presented at the NBER Conference on RiskAspects of Investment-based Social Security Reform.

Murphy, Kevin, and Finis Welch, 1992, The Structure of Wages, Quarterly Journal of Economics 107, 285-326.

Peled, Dan, 1982, Informational Diversity over Time and the Optimality of Monetary Equilibria, Journal of Economic Theory 28, 255-274.

Poterba, James, 1998, Population Age Structure and Asset Returns: An Empirical Investigation, NBER Working Paper No. 6774.

Shiller, Robert, 1998, Social Security and Institutions for Intergenerational, Intragenerational and International Risk Sharing, Paper presented at the Carnegie Rochester Conference on Public Policy. Smetters, Kent, 1997, Investing the Social Security Trust Fund into Equities: Unmasking the Large Hidden Actuarial Tax Liabilities on Future Generations, mimeo, Congressional Budget Office.

Smetters, Kent, 1999, Arbitrage Pricing of Unfunded Pension Guarantees: Rationale and Computations, Paper presented at the NBER Conference on Risk-Aspects of Investment-based Social Security Reform.

Smith, Alasdair, 1982, Intergenerational Transfers as Social Insurance, Journal of Public Economics 19, 97-106.

Storesletten, Kjetil, Chris Telmer, and Amir Yaron, 1998, The Risk-Sharing Implications of Alternative Social Security Arrangements, Paper presented at the Carnegie-Rochester Conference on Public Policy. Temple, Jonathan, 1998, The New Growth Evidence, mimeo, Oxford University. Welch, Finis, 1979, Effects of Cohort Size on Earnings: The Baby Boom Babies' Financial Bust, Journal of Political Economy 85, S65-S97. 


\section{Table 1: Macroeconomic Dynamics with Defined-Benefits}

Impact on
Elasticity Coefficients

(Symbols defined below)
Numerical

Example

Panel A. Shocks to the current workforce, $\mu_{1 t}$ and $b_{t-1}$ :

$$
\begin{array}{ll}
\text { Retirees: } & \pi_{\mathrm{C} 2 \mu 1}=\pi_{\mathrm{C} 2 \mathrm{~b} 1}=\gamma_{\mathrm{c} 2 \mathrm{nw}}>0 \\
\text { Workers: } & \pi_{\mathrm{C} 1 \mu 1}=\pi_{\mathrm{C} 1 \mathrm{~b} 1}=-\Delta_{\mathrm{C}} \cdot\left[\alpha-\frac{\theta}{1-\theta}\right] \\
& \\
& \text { is negative, provided } \alpha>\frac{\theta}{1-\theta} . \\
\text { Investment: } & \pi_{\mathrm{k} \mu 1}=\pi_{\mathrm{kb} 1}=-\Delta_{\mathrm{k}} \cdot\left[\alpha-\frac{\theta}{1-\theta}\right]<0
\end{array}
$$

Panel B. Shocks to the current birthrate, $b_{t}$ :

Retirees:

Workers:

Investment :

$$
\pi_{\mathrm{C} 2 \mathrm{~b}}=0
$$$$
\pi_{\mathrm{C} 1 \mathrm{~b}}=\left(1-\Delta_{\mathrm{C}} \cdot\left(\mathrm{C}^{1} / \mathrm{A}\right) / \mathrm{y}^{1}\right) \cdot\left(\gamma_{\mathrm{C} 2 \mathrm{nw}}-\pi_{\mathrm{Rk}} / \eta+\gamma_{\rho} / \eta\right)
$$$$
\pi_{\mathrm{kb}}=-\Delta_{\mathrm{k}} \cdot\left(\mathrm{c}^{1 / \mathrm{A}}\right) / \mathrm{y}^{1} \cdot\left[\gamma_{\mathrm{c} 2 \mathrm{nw}}-\pi_{\mathrm{Rk}} / \eta+\gamma_{\rho} / \eta\right]
$$

0

Panel C. Shocks to the current length of life, $\phi^{u_{t}}$ and $\phi^{e}{ }_{t-1}$ :

Retirees:

$\pi_{\mathrm{C} 2 \phi u}=\pi_{\mathrm{C} 2 \phi e 1}=-\gamma_{\mathrm{C} 2 \phi}<0$

Workers :

$$
\pi_{\mathrm{c} 1 \phi u}=\pi_{\mathrm{c} 1 \phi e 1}=-\Delta_{\mathrm{C}} \cdot \frac{\theta}{1-\theta}<0
$$

Investment :

$$
\pi_{\mathrm{k} \phi \mathrm{u}}=\pi_{\mathrm{k} \phi e 1}=-\Delta_{\mathrm{k}} \cdot \frac{\theta}{1-\theta}<0
$$

Panel D. Shocks to life expectancy (future length of life), $\phi^{e_{t}}$ :

$$
\begin{array}{llr}
\text { Retirees: } & \pi_{\mathrm{C} 2 \phi e}=0 & 0 \\
\text { Workers: } & \pi_{\mathrm{C} 1 \phi e}=-\left(1-\Delta_{\mathrm{C}} \cdot\left(\mathrm{C}^{1 / \mathrm{A}}\right) / \mathrm{y}^{1}\right) \cdot \gamma_{\mathrm{C} 2 \phi}<0 & -0.288 \\
\text { Investment: } & \pi_{\mathrm{k} \phi e}=\Delta_{\mathrm{k}} \cdot\left(\mathrm{C}^{1 / \mathrm{A})} / \mathrm{y}^{1} \cdot \gamma_{\mathrm{c} 2 \phi}>0\right. & 0.865
\end{array}
$$

Panel E. Changes in lagged capital and productivity, $k_{t-1}$ and $a_{t}$ :

Retirees:

Workers:

Investment :
$\pi_{\mathrm{C} 2 \mathrm{k}}=-\pi_{\mathrm{C} 2 \mathrm{a}}=\gamma_{\mathrm{c} 2 \mathrm{k}}>0$

0.333

0.278

0.500 


\section{Notes to Table 1:}

1. The impact on retirees, on workers, and on investment refers to the impact of the shock(s) named in the panel header on the variables $\left(c^{\hat{1}} / A\right)_{t},\left(c^{2} / A\right)_{t}$ and $\hat{k}_{t}$. Since these variables are scaled by the productivity trend $A_{t}$, the coefficients for productivity shocks at are negative. The impact of productivity shocks on consumption and investment levels, $1+\pi_{\mathrm{c} 2 \mathrm{a}}>0,1+\pi_{\mathrm{c} 1 \mathrm{a}}>0$, and $1+\pi_{\mathrm{ka}}>0$, are nonetheless positive.

2. The last column refers to the elasticity values in the numerical example described in the text.

3. Variables without time subscripts refer to the steady state. The symbols not already defined in the text are as follows:

$\delta^{\star}=\frac{\delta \cdot \mathrm{k} / \mathrm{an}}{\left(\mathrm{C}^{2} / \mathrm{A}\right) \cdot \phi /\left(1+\mathrm{n}^{\mathrm{W}}\right)} \in(0,1)$, share of old capital in retiree income.

$\gamma_{\mathrm{c} 2 \mathrm{k}}=\left(1-\delta^{*}\right) \cdot \alpha+\delta^{\star} \in(0,1)$, impact of a higher capital-labor ratio on the old. $\gamma_{\mathrm{c} 2 \mathrm{nw}}=1-\gamma_{\mathrm{c} 2 \mathrm{k}}-\left(1-\delta^{\star}\right) \cdot \frac{\theta \cdot(1-\alpha)}{\alpha+\theta \cdot(1-\alpha)}=\frac{\left(1-\delta^{\star}\right) \cdot(1-\alpha) \cdot \alpha \cdot(1-\theta)}{\alpha+\theta \cdot(1-\alpha)} \in(0,1)$, impact of a

higher current labor force on the old.

$\gamma_{c 2 \phi}=1-\left(1-\delta^{\star}\right) \cdot \frac{\theta \cdot(1-\alpha)}{\alpha+\theta \cdot(1-\alpha)} \in(0,1)$, impact (absolute value) of a longer life span on the old.

$\pi_{\mathrm{Rk}}=\left(1-\delta / \mathrm{R}^{\mathrm{k}}\right) \cdot(1-\alpha) \in(0,1)$, impact (absolute value) of a higher capitallabor ratio on the return to capital.

$\mathrm{y}^{1}=\mathrm{w} / \mathrm{A} \cdot(1-\theta)$, income of the young scaled by productivity.

$\Delta_{C}=\frac{\left[\gamma_{c 2 k}+\pi_{R k} / \eta\right]}{\left(C^{1} / A\right) / y^{1} \cdot\left[\gamma_{c 2 k}+\pi_{R k} / \eta+\gamma_{c 2} \beta \cdot \pi_{\beta k}\right]+k / y^{1}}>0$, marginal effect on consumption when the income of the young rises.

$\Delta_{\mathrm{k}}=\frac{1}{\left(\mathrm{c}^{1 / A}\right) / \mathrm{y}^{1} \cdot\left[\gamma_{\mathrm{c} 2 \mathrm{k}}+\pi_{\mathrm{Rk}} / \eta+\gamma_{\mathrm{c} 2} \cdot \pi_{\beta \mathrm{k}}\right]+\mathrm{k} / \mathrm{y}^{1}}>0$, marginal effect on capital investment when the income of the young rises. 


\section{Table 2: Dynamics with variable Social security Benefits}

\section{Impact on Elasticity Coefficients}

Panel A. Shocks to the current workforce, $\mu_{1 \mathrm{t}}$ and $\mathrm{b}_{t-1}$ :
Retirees:
$\pi_{\mathrm{c} 2 \mu 1}=\gamma_{\mathrm{c} 2 \mathrm{nw}}+\gamma_{\mathrm{c} 2 \beta} \cdot \pi_{\beta \mu 1}$,
$\pi_{\mathrm{c} 2 \mathrm{~b} 1}=\gamma_{\mathrm{c} 2 \mathrm{nw}}+\gamma_{\mathrm{c} 2 \beta} \cdot \pi_{\beta \mathrm{b} 1}$
Workers:
$\pi_{\mathrm{C} 1 \mu 1}=-\Delta_{\mathrm{C}} \cdot\left[\alpha-\frac{\theta}{1-\theta}\right]-\Delta_{\mathrm{C}} \cdot \frac{\theta}{1-\theta} \cdot \pi_{\beta \mu 1}$,
$\pi_{\mathrm{C} 1 \mathrm{~b} 1}=-\Delta_{\mathrm{C}} \cdot\left[\alpha-\frac{\theta}{1-\theta}\right]-\Delta_{\mathrm{C}} \cdot \frac{\theta}{1-\theta} \cdot \pi_{\beta \mathrm{b} 1}$
Investment :

$$
\pi_{\mathrm{k} \mu 1}=-\Delta_{\mathrm{k}} \cdot\left[\alpha-\frac{\theta}{1-\theta}\right]-\Delta_{\mathrm{k}} \cdot \frac{\theta}{1-\theta} \cdot \pi_{\beta \mu 1}
$$
$\pi_{\mathrm{kb} 1}=-\Delta_{\mathrm{k}} \cdot\left[\alpha-\frac{\theta}{1-\theta}\right]-\Delta_{\mathrm{k}} \cdot \frac{\theta}{1-\theta} \cdot \pi_{\beta \mathrm{b} 1}$

Panel B. Shocks to the current birthrate, $b_{t}$ :

$$
\begin{aligned}
& \text { Retirees: } \quad \pi_{\mathrm{c} 2 \mathrm{~b}}=\gamma_{\mathrm{c} 2} \beta \cdot \pi_{\beta \mathrm{b}} \\
& \text { Workers: } \quad \pi_{\mathrm{c} 1 \mathrm{~b}}=\left(1-\Delta_{\mathrm{C}} \cdot\left(\mathrm{c}^{1 / A}\right) / \mathrm{y}^{1}\right) \cdot\left[\gamma_{\mathrm{c} 2 \mathrm{nw}}-\left(1-\delta / \mathrm{R}^{\mathrm{k}}\right) \cdot(1-\alpha) / \eta+\gamma_{\rho} / \eta\right] \\
& -\Delta_{C} \cdot \frac{\theta}{1-\theta} \cdot \pi_{\beta b}+\left(1-\Delta_{C} \cdot\left(C^{1 / A}\right) / y^{1}\right) \cdot \gamma_{C 2 \beta} \cdot \pi_{\beta b 1} \\
& \text { Investment: } \quad \pi_{\mathrm{kb}}=-\Delta_{\mathrm{k}} \cdot\left(\mathrm{c}^{1 / \mathrm{A}}\right) / \mathrm{y}^{1} \cdot\left[\gamma_{\mathrm{c} 2 \mathrm{nw}}-\left(1-\delta / \mathrm{R}^{\mathrm{k}}\right) \cdot(1-\alpha) / \eta+\gamma_{\rho} / \eta\right] \\
& -\Delta_{\mathrm{k}} \cdot \frac{\theta}{1-\theta} \cdot \pi_{\beta \mathrm{b}}-\Delta_{\mathrm{k}} \cdot\left(\mathrm{c}^{1 / \mathrm{A}}\right) / \mathrm{y}^{1} \cdot \gamma_{\mathrm{c} 2 \beta} \cdot \pi_{\beta \mathrm{b} 1}
\end{aligned}
$$

Panel C. Shocks to the current length of life, $\phi^{u_{t}}$ and $\phi^{e_{t-1}}$ :

$$
\begin{array}{lll}
\text { Retirees: } & \pi_{\mathrm{c} 2 \phi \mathrm{u}}=-\gamma_{\mathrm{c} 2 \phi}+\gamma_{\mathrm{c} 2} \cdot \pi_{\beta \phi \mathrm{u}}, & \pi_{\mathrm{c} 2 \phi \mathrm{e} 1}=-\gamma_{\mathrm{c} 2 \phi}+\gamma_{\mathrm{c} 2 \beta} \cdot \pi_{\beta \mathrm{b} 1} \\
\text { Workers: } & \pi_{\mathrm{c} 1 \phi \mathrm{u}}=-\Delta_{\mathrm{C}} \cdot \frac{\theta}{1-\theta}-\Delta_{\mathrm{C}} \cdot \frac{\theta}{1-\theta} \cdot \pi_{\beta \phi u}, & \pi_{\mathrm{C} 1 \phi \mathrm{e} 1}=-\Delta_{\mathrm{C}} \cdot \frac{\theta}{1-\theta}-\Delta_{\mathrm{C}} \cdot \frac{\theta}{1-\theta} \cdot \pi_{\beta \phi e 1} \\
& \pi_{\mathrm{k} \phi \mathrm{u}}=-\Delta_{\mathrm{k}} \cdot \frac{\theta}{1-\theta}-\Delta_{\mathrm{k}} \cdot \frac{\theta}{1-\theta} \cdot \pi_{\beta \phi \mathrm{u}}, & \pi_{\mathrm{k} \phi \mathrm{e} 1}=-\Delta_{\mathrm{k}} \cdot \frac{\theta}{1-\theta}-\Delta_{\mathrm{k}} \cdot \frac{\theta}{1-\theta} \cdot \pi_{\beta \phi e 1}
\end{array}
$$

Panel D. Shocks to current life-expectancy, $\phi^{e_{t}}$ :

$$
\begin{aligned}
& \text { Retirees: } \quad \pi_{\mathrm{c} 2 \phi e}=\gamma_{\mathrm{c} 2} \beta \cdot \pi_{\beta \phi e} \\
& \text { Workers: } \quad \pi_{c 1 \phi e}=-\left(1-\Delta_{C} \cdot\left(C^{1 / A}\right) / y^{1}\right) \cdot\left(\gamma_{c 2 \phi}-\gamma_{c 2 \beta} \cdot \pi_{\beta \phi e 1}\right)-\Delta_{C} \cdot \frac{\theta}{1-\theta} \cdot \pi_{\beta \phi e} \\
& \text { Investment : } \quad \pi_{\mathrm{k} \phi \mathrm{e}}=\Delta_{\mathrm{k}} \cdot\left(\mathrm{c}^{1 / \mathrm{A}}\right) / \mathrm{y}^{1} \cdot\left(\gamma_{\mathrm{c} 2 \phi}-\gamma_{\mathrm{c} 2} \beta \pi_{\beta \phi e 1}\right)-\Delta_{\mathrm{k}} \cdot \frac{\theta}{1-\theta} \cdot \pi_{\beta \phi e}
\end{aligned}
$$

Panel E. Changes in lagged capital and productivity, $k_{t-1}$ and $a_{t}$ :

$$
\begin{aligned}
& \text { Retirees: } \quad \pi_{\mathrm{c} 2 \mathrm{k}}=\gamma_{\mathrm{c} 2 \mathrm{k}}+\gamma_{\mathrm{c} 2 \beta} \cdot \pi_{\beta \mathrm{k}}, \quad \pi_{\mathrm{c} 2 \mathrm{a}}=-\gamma_{\mathrm{c} 2 \mathrm{k}}+\gamma_{\mathrm{c} 2} \cdot \pi_{\beta a} \\
& \text { Workers: } \quad \pi_{\mathrm{C} 1 \mathrm{k}}=\Delta_{\mathrm{C}} \cdot \alpha-\Delta_{\mathrm{C}} \cdot \frac{\theta}{1-\theta} \cdot \pi_{\beta \mathrm{k}}, \quad \pi_{\mathrm{C} 1 \mathrm{a}}=\Delta_{\mathrm{C}} \cdot \alpha-\Delta_{\mathrm{C}} \cdot \frac{\theta}{1-\theta} \cdot \pi_{\beta a} \\
& \text { Investment: } \quad \pi_{\mathrm{kk}}=\Delta_{\mathrm{k}} \cdot \alpha-\Delta_{\mathrm{k}} \cdot \frac{\theta}{1-\theta} \cdot \pi_{\beta \mathrm{k}}, \pi_{\mathrm{ka}}=-\Delta_{\mathrm{k}} \cdot \alpha-\Delta_{\mathrm{k}} \cdot \frac{\theta}{1-\theta} \cdot \pi_{\beta a}
\end{aligned}
$$

Notes: The notation is as in Table 1 . In addition, define $\gamma_{c 2 \beta}=\left(1-\delta^{\star}\right) \cdot \frac{\theta \cdot(1-\alpha)}{\alpha+\theta \cdot(1-\alpha)}>0$. 


\section{Table 3: Alternative Policies in the Numerical Example}

Panel A. Shocks to the workforce, $\mu_{1 t}$ and $b_{t-1}$ :

\begin{tabular}{|c|c|c|c|c|c|}
\hline Alternative Systems: & DB & $\mathrm{DC}$ & Privatized & Prefunded & Prefunded \\
\hline Shock to: & $\mu_{1 t}$ or $b_{t-1}$ & $\mu_{1 t}$ or $b_{t-1}$ & $\mu_{1 t}$ or $b_{t-1}$ & $\mu_{1 t}$ & $\mathrm{~b}_{t-1}$ \\
\hline Policy coefficient & 0 & 1.0 & $\mathrm{~N} / \mathrm{A}$ & 0 & 0.5 \\
\hline Impact on Retirees & 0.436 & 0.667 & $\begin{array}{c}0.667 \\
(=\mathrm{DC} \text { Case })\end{array}$ & $\begin{array}{c}0.436 \\
(=\mathrm{DB} \text { Case })\end{array}$ & $\begin{array}{c}0.551 \\
\text { (in between) }\end{array}$ \\
\hline Impact on Workers & -0.131 & -0.278 & $\begin{array}{c}-0.278 \\
(=\mathrm{DC} \text { Case })\end{array}$ & $\begin{array}{c}-0.131 \\
(=\mathrm{DB} \text { Case })\end{array}$ & $\begin{array}{c}-0.204 \\
\text { (in between) }\end{array}$ \\
\hline Impact on Investment & -0.235 & -0.500 & -0.500 & -0.235 & -0.368 \\
\hline
\end{tabular}

Panel B. Shocks to the length of life, $\phi^{u_{t}}$ and $\phi^{e_{t-1}}$ :

\begin{tabular}{|c|c|c|c|c|c|}
\hline Alternative Systems: & DB & $\mathrm{DC}$ & Privatized & Prefunded & Prefunded \\
\hline Shock to: & $\phi_{t}^{u}$ or $\phi_{t-1}^{e_{t}}$ & $\phi_{t}^{u}$ or $\phi_{t-1}^{e_{t}}$ & $\phi_{t}^{u}$ or $\phi_{t-1}^{e}$ & $\phi^{u_{t}}$ & $\phi^{e}{ }_{t-1}$ \\
\hline Policy coefficient & 0 & $-1 \cdot 0$ & $\mathrm{~N} / \mathrm{A}$ & 0 & -0.5 \\
\hline Impact on Retirees & -0.769 & -1.0 & $\begin{array}{c}-1.0 \\
(=\text { DC Case) }\end{array}$ & $\begin{array}{c}-0.769 \\
(=\mathrm{DB} \text { Case) }\end{array}$ & $\begin{array}{c}-0.885 \\
\text { (in between) }\end{array}$ \\
\hline Impact on Workers & -0.147 & 0.0 & $\begin{array}{c}0.0 \\
(=\mathrm{DC} \text { Case })\end{array}$ & $\begin{array}{c}-0.147 \\
(=\mathrm{DB} \text { Case })\end{array}$ & $\begin{array}{c}-0.074 \\
\text { (in between) }\end{array}$ \\
\hline Impact on Investment & -0.265 & 0.0 & 0.0 & -0.265 & -0.111 \\
\hline
\end{tabular}

Notes: The notation is as in Tables $1-2$.

For DB, DC and privatized social security, $\mu_{1 t} \& b_{t-1}$ and $\phi_{t}^{u_{t}} \delta^{e} \phi_{t-1}$, respectively, have the same effects.

In the conditionally prefunded system, policy coefficients are generally in the range $\pi_{\beta b 1} \in(0,+1)$ and $\pi_{\beta \phi e 1} \in(-1,0)$. For the numerical example, I use +0.5 and -0.5 , respectively. 


\section{Table 4: Macroeconomic Dynamics without Annuities Markets}

Impact on

Elasticity Coefficients

Numerical

Example

Panel A. Shocks to retiree survival without annuities, $\mu^{u_{2 t}}$ and $\mu^{e_{2}}{ }_{-1}$ :
Retirees:
$\pi_{\mathrm{c} 2 \mu 2 \mathrm{u}}=\gamma_{\mathrm{c} 2 \beta} \cdot \pi_{\beta \mu 2 \mathrm{u}}, \quad \pi_{\mathrm{c} 2 \mu 2 \mathrm{e} 1}=\gamma_{\mathrm{c} 2 \beta} \cdot \pi_{\beta \mu 2 \mathrm{e} 1}$
where $\gamma_{c 2 \beta}=\left(1-\delta^{*}\right) \cdot \frac{\theta / \mu_{2} \cdot(1-\alpha)}{\alpha+\theta / \mu_{2} \cdot(1-\alpha)}>0$
Workers:
$\pi_{\mathrm{C} 1 \mu 2 \mathrm{u}}=-\Delta_{\mathrm{C}} \cdot\left[(1-\mathrm{q}) \cdot\left(1+\pi_{\beta \mu 2 \mathrm{u}}\right)+\mathrm{q} \cdot \frac{\mu_{2}}{1-\mu_{2}}\right] \cdot \frac{\theta}{1-\theta^{\prime}}$
$\pi_{\mathrm{C} 1 \mu 2 \mathrm{e} 1}=-\Delta_{\mathrm{C}} \cdot\left[(1-\mathrm{q}) \cdot\left(1+\pi_{\beta \mu 2 \mathrm{e} 1}\right)+\mathrm{q} \cdot \frac{\mu_{2}}{1-\mu_{2}}\right] \cdot \frac{\theta}{1-\theta}$
Investment: $\quad \pi_{\mathrm{k} \mu 2 \mathrm{u}}=-\Delta_{\mathrm{k}} \cdot\left[(1-\mathrm{q}) \cdot\left(1+\pi_{\beta \mu 2 \mathrm{u}}\right)+\mathrm{q} \cdot \frac{\mu_{2}}{1-\mu_{2}}\right) \cdot \frac{\theta}{1-\theta^{\prime}}$
$\pi_{\mathrm{k} \mu 2 \mathrm{e} 1}=-\Delta_{\mathrm{k}} \cdot\left[(1-\mathrm{q}) \cdot\left(1+\pi_{\beta \mu 2 \mathrm{e} 1}\right)+\mathrm{q} \cdot \frac{\mu_{2}}{1-\mu_{2}}\right) \cdot \frac{\theta}{1-\theta}$

Panel B. Shocks to future retiree survival without annuities, $\mu^{e_{2 t}}$ :
Retirees :
$\pi_{\mathrm{c} 2 \mu 2 \mathrm{e}}=\gamma_{\mathrm{c} 2 \beta} \cdot \pi_{\beta \mu 2 \mathrm{e}}$
Workers:
$\pi_{\mathrm{C} 1 \mu 2 \mathrm{e}}=-\left(1-\Delta_{\mathrm{C}} \cdot\left(\mathrm{C}^{1} / \mathrm{A}\right) / \mathrm{y}^{1}\right) \cdot\left(1 / \eta-\gamma_{\mathrm{C} 2} \beta \cdot \pi_{\beta \mu 2 \mathrm{e} 1}\right)$
Investment :$$
\pi_{k \mu 2 e}=\Delta_{k} \cdot\left(c^{1 / A}\right) / y^{1} \cdot\left(1 / \eta-\gamma_{c 2} \beta \cdot \pi_{\beta \mu 2 e 1}\right)
$$$$
-\Delta_{\mathrm{k}}^{*} \cdot \frac{\theta}{1-\theta} \cdot \pi_{\beta \mu 2 \mathrm{e}}
$$

Panel C. Shocks to the current workforce, $\mu_{1 \mathrm{t}}$ and $\mathrm{b}_{t-1}:^{*}$

$$
\begin{aligned}
& \text { Retirees: } \quad \pi_{\mathrm{c} 2 \mu 1}=\gamma_{\mathrm{c} 2 \mathrm{nw}}+\gamma_{\mathrm{c} 2} \cdot \pi_{\beta \mu 1}, \quad \pi_{\mathrm{c} 2 \mathrm{~b} 1}=\gamma_{\mathrm{c} 2 \mathrm{nw}}+\gamma_{\mathrm{c} 2 \beta} \cdot \pi_{\beta \mathrm{b} 1} \\
& \text { where } \gamma_{\mathrm{c} 2 \mathrm{nw}}=\left(1-\delta^{\star}\right) \cdot\left(1-\alpha-\frac{\theta / \mu_{2} \cdot(1-\alpha)}{\alpha+\theta / \mu_{2} \cdot(1-\alpha)}\right)>0 \\
& \text { Workers: } \quad \pi_{\mathrm{C} 1 \mu 1}=-\Delta_{\mathrm{C}} \cdot\left[(1-\mathrm{q}) \cdot \alpha+\mathrm{q} \cdot \pi_{\mathrm{Rk}}-(1-\mathrm{q}) \frac{\theta}{1-\theta}\right]-\Delta_{\mathrm{C}}{ }^{\star} \cdot \frac{\theta}{1-\theta} \cdot \pi_{\beta \mu 1} \\
& \pi_{\mathrm{C} 1 \mathrm{~b} 1}=-\Delta_{\mathrm{C}} \cdot\left[(1-\mathrm{q}) \cdot \alpha+\mathrm{q} \cdot \pi_{\mathrm{Rk}}-(1-\mathrm{q}) \frac{\theta}{1-\theta}\right]-\Delta_{\mathrm{C}}{ }^{\star} \cdot \frac{\theta}{1-\theta} \cdot \pi_{\beta \mathrm{b} 1} \\
& \text { Investment: } \quad \pi_{\mathrm{k} \mu 1}=-\Delta_{\mathrm{k}} \cdot\left[(1-\mathrm{q}) \cdot \alpha+\mathrm{q} \cdot \pi_{\mathrm{Rk}}-(1-\mathrm{q}) \frac{\theta}{1-\theta}\right]-\Delta_{\mathrm{k}}{ }^{*} \cdot \frac{\theta}{1-\theta} \cdot \pi_{\beta \mu 1} \\
& \pi_{\mathrm{kb} 1}=-\Delta_{\mathrm{k}} \cdot\left[(1-\mathrm{q}) \cdot \alpha+\mathrm{q} \cdot \pi_{\mathrm{Rk}}-(1-\mathrm{q}) \frac{\theta}{1-\theta}\right]-\Delta_{\mathrm{k}}{ }^{*} \cdot \frac{\theta}{1-\theta} \cdot \pi_{\beta \mathrm{b} 1}
\end{aligned}
$$




\section{Table 4 (continued):}

$$
\begin{aligned}
& \text { Panel D. Shocks to the current length of life, } \phi^{u_{t}} \text { and } \phi^{e_{t-1}}:^{*} \\
& \text { Retirees: } \quad \pi_{\mathrm{c} 2 \phi u}=-\gamma_{\mathrm{c} 2 \phi}+\gamma_{\mathrm{c} 2} \cdot \pi_{\beta \phi \mathrm{u}}, \pi_{\mathrm{c} 2 \phi \mathrm{e} 1}=-\gamma_{\mathrm{c} 2 \phi}+\gamma_{\mathrm{c} 2 \beta} \cdot \pi_{\beta \mathrm{b} 1} \\
& \text { where } \gamma_{\mathrm{c} 2 \phi}=1-\left(1-\delta^{\star}\right) \cdot \frac{\theta / \mu_{2} \cdot(1-\alpha)}{\alpha+\theta / \mu_{2} \cdot(1-\alpha)}>0 \\
& \text { Workers: } \quad \pi_{\mathrm{c} 1 \phi u}=-\Delta^{*}{ }_{\mathrm{c}} \cdot \frac{\theta}{1-\theta} \cdot\left(\pi_{\beta \phi u}+1\right), \pi_{\mathrm{c} 1 \phi e 1}=-\Delta^{*}{ }_{\mathrm{c}} \cdot \frac{\theta}{1-\theta} \cdot\left(\pi_{\beta \phi e 1}+1\right) \\
& \text { Investment : } \quad \pi_{\mathrm{k} \phi \mathrm{u}}=-\Delta_{\mathrm{k}}^{*} \cdot \frac{\theta}{1-\theta} \cdot\left(\pi_{\beta \phi \mathrm{u}}+1\right), \quad \pi_{\mathrm{k} \phi \mathrm{e} 1}=-\Delta_{\mathrm{k}}^{*} \cdot \frac{\theta}{1-\theta} \cdot\left(\pi_{\beta \phi e 1}+1\right) \\
& \text { Panel E. Shocks to the current birthrate, } b_{t}:{ }^{*} \\
& \text { Retirees : } \quad \pi_{\mathrm{c} 2 \mathrm{~b}}=\gamma_{\mathrm{c} 2 \beta} \cdot \pi_{\beta \mathrm{b}} \\
& \text { Workers : } \quad \pi_{\mathrm{C} 1 \mathrm{~b}}=\left(1-\Delta_{\mathrm{C}} \cdot\left(\mathrm{C}^{1 / A}\right) / \mathrm{y}^{1}\right) \cdot\left[\gamma_{\mathrm{C} 2 \mathrm{nw}}-\pi_{\mathrm{Rk}} / \eta+\gamma_{\rho} / \eta+\gamma_{\mathrm{C} 2 \beta} \cdot \pi_{\beta \mathrm{b} 1}\right]-\Delta_{\mathrm{C}}{ }^{\star} \cdot \frac{\theta}{1-\theta} \cdot \pi_{\beta \mathrm{b}} \\
& \text { Investment : } \quad \pi_{\mathrm{kb}}=-\Delta_{\mathrm{k}} \cdot\left(\mathrm{c}^{1 / \mathrm{A}}\right) / \mathrm{y}^{1} \cdot\left[\gamma_{\mathrm{c} 2 \mathrm{nw}}-\pi_{\mathrm{Rk}} / \eta+\gamma_{\rho} / \eta+\gamma_{\mathrm{c} 2} \cdot \pi_{\beta \mathrm{b} 1}\right]-\Delta^{*}{ }_{\mathrm{k}} \cdot \frac{\theta}{1-\theta} \cdot \pi_{\beta \mathrm{b}} \\
& \text { Retirees: } \quad \pi_{\mathrm{c} 2 \phi e}=\gamma_{\mathrm{c} 2 \beta} \cdot \pi_{\beta \phi e} \\
& \text { Workers: } \quad \pi_{\mathrm{C} 1 \phi e}=-\left(1-\Delta_{\mathrm{C}} \cdot\left(\mathrm{C}^{1 / A}\right) / \mathrm{y}^{1}\right) \cdot\left(\gamma_{\mathrm{C} 2 \phi}-\gamma_{\mathrm{C} 2} \beta \cdot \pi_{\beta \phi e 1}\right)-\Delta_{\mathrm{C}}{ }^{*} \cdot \frac{\theta}{1-\theta} \cdot \pi_{\beta \phi e} \\
& \text { Investment : } \quad \pi_{\mathrm{k} \phi e}=\Delta_{\mathrm{k}} \cdot\left(\mathrm{c}^{1 / A}\right) / \mathrm{y}^{1} \cdot\left(\gamma_{\mathrm{c} 2 \phi}-\gamma_{\mathrm{c} 2} \beta \cdot \pi_{\beta \phi e 1}\right)-\Delta_{\mathrm{k}}^{*} \cdot \frac{\theta}{1-\theta} \cdot \pi_{\beta \phi e} \\
& \text { Panel G. Changes in lagged capital and productivity, } k_{t-1} \text { and } a_{t}: \text { * } \\
& \begin{array}{ll}
\text { Retirees } & \pi_{\mathrm{c} 2 \mathrm{k}}=\gamma_{\mathrm{c} 2 \mathrm{k}}+\gamma_{\mathrm{c} 2 \beta} \cdot \pi_{\beta \mathrm{k}}, \pi_{\mathrm{c} 2 \mathrm{a}}=-\gamma_{\mathrm{c} 2 \mathrm{k}}+\gamma_{\mathrm{c} 2 \beta} \cdot \pi_{\beta a} \\
\text { Workers: } & \pi_{\mathrm{c} 1 \mathrm{k}}=\Delta_{\mathrm{C}} \cdot\left[(1-\mathrm{q}) \cdot \alpha+\mathrm{q} \cdot \pi_{\mathrm{Rk}}\right]-\Delta_{\mathrm{C}}{ }^{\star} \cdot \frac{\theta}{1-\theta} \cdot \pi_{\beta \mathrm{k}} \\
& \pi_{\mathrm{c} 2 \mathrm{a}}=-\Delta_{\mathrm{C}} \cdot\left[(1-\mathrm{q}) \cdot \alpha+\mathrm{q} \cdot \pi_{\mathrm{Rk}}\right]-\Delta_{\mathrm{C}}{ }^{\star} \cdot \frac{\theta}{1-\theta} \cdot \pi_{\beta a} \\
\text { Investment }: & \pi_{\mathrm{kk}}=\Delta_{\mathrm{k}} \cdot\left[(1-\mathrm{q}) \cdot \alpha+\mathrm{q} \cdot \pi_{\mathrm{Rk}}\right]-\Delta_{\mathrm{k}}{ }^{\star} \cdot \frac{\theta}{1-\theta} \cdot \pi_{\beta \mathrm{k}} \\
& \pi_{\mathrm{ka}}=-\Delta_{\mathrm{k}} \cdot\left[(1-\mathrm{q}) \cdot \alpha+\mathrm{q} \cdot \pi_{\mathrm{Rk}}\right]-\Delta_{\mathrm{k}}{ }^{\star} \cdot \frac{\theta}{1-\theta} \cdot \pi_{\beta a}
\end{array}
\end{aligned}
$$

\section{Notes:}

1. The notation is as in Tables 1-2, except for the following symbols:

$$
\begin{aligned}
& \mathrm{q}=\mathrm{Q}^{1} /\left(\mathrm{w} \cdot(1-\theta)+\mathrm{Q}^{1}\right)=\text { share of bequests in worker's income; } \\
& \Delta_{\mathrm{C}}{ }^{*}=\Delta_{\mathrm{C}} \cdot(1-\mathrm{q}), \Delta_{\mathrm{k}}{ }^{*}=\Delta_{\mathrm{k}} \cdot(1-\mathrm{q}) .
\end{aligned}
$$

* As in Table 2, but with modified coefficients if $q \neq 0$ or $\mu_{2} \neq 0$. 


\section{Table 5: Optimal Policy Responses to Demographic Shocks}

Policy response to changes in the current workforce:

$$
\pi^{\star} \beta \mu 1=\pi^{\star} \beta \mathrm{b} 1=-\frac{\gamma_{\mathrm{C} 2 \mathrm{nw}}+\Delta_{\mathrm{C}} \cdot q \cdot \pi_{\mathrm{Rk}}+\Delta_{\mathrm{C}}^{*} \cdot[\alpha-\theta /(1-\theta)]}{\gamma_{\mathrm{C} 2} \beta+\Delta^{*}{ }_{\mathrm{C}} \cdot \theta /(1-\theta)}
$$

Policy response to changes in the current birthrate:

$$
\pi^{\star} \beta b=\left(1-\Delta_{C} \cdot \frac{\left(C^{1} / A\right)}{y^{1}}\right) \cdot \frac{\gamma_{c 2 n w}-\pi_{R k} / \eta+\gamma_{c 2 \beta} \cdot \pi_{\beta b 1}}{\gamma_{c 2}+\Delta^{*}{ }_{C} \cdot \theta /(1-\theta)}-\Delta_{C} \cdot \frac{\left(C^{1} / A\right)}{y^{1}} \cdot \frac{\gamma_{\rho} / \eta}{\gamma_{c 2} \beta^{+\Delta^{*}}{ }_{C} \cdot \theta /(1-\theta)}
$$

Policy response to changes in the current length of life:

$$
\pi_{\beta \phi u}^{\star}=\pi_{\beta \phi e 1}^{\star}=\frac{\gamma_{c 2 \phi-\Delta_{c}^{*} \cdot \theta /(1-\theta)}}{\gamma_{c 2 \beta^{+} \Delta_{c}^{*} \cdot \theta /(1-\theta)}}
$$

Policy response to changes in current retiree survival without annuities:

$$
\pi^{\star} \beta \mu 2 \mathrm{u}=\pi^{\star} \beta \mu 2 \mathrm{e} 1=-\frac{\Delta_{\mathrm{C}} \cdot\left[1-\mathrm{q}+\mathrm{q} \cdot \mu_{2} /\left(1-\mu_{2}\right)\right] \cdot \theta /(1-\theta)}{\gamma_{\mathrm{C} 2} \beta^{+\Delta^{*}{ }_{\mathrm{C}} \cdot \theta /(1-\theta)}}
$$

Policy response to changes in the future length of life:

$$
\pi_{\beta \phi e}^{\star}=-\left(1-\Delta_{C} \cdot \frac{\left(c^{1 / A}\right)}{y^{1}}\right) \cdot \frac{\gamma_{c 2 \phi}-\gamma_{c 2 \beta} \cdot \pi_{\beta \phi e 1}}{\gamma_{c 2} \beta^{+\Delta^{*}{ }_{c} \cdot \theta /(1-\theta)}}
$$

Policy response to changes in future retiree survival without annuities:

$$
\pi^{\star} \beta \mu 2 e=-\left(1-\Delta_{C} \cdot \frac{\left(c^{1 / A}\right)}{y^{1}}\right) \cdot \frac{1 / \eta-\gamma_{c 2 \beta} \cdot \pi_{\beta \mu 2 e 1}}{\gamma_{c 2} \beta^{+\Delta^{*}{ }_{C} \cdot \theta /(1-\theta)}}
$$

Note: The notation is as in Tables $1-2$ and 4 . The stars ( ${ }^{*}$ denote efficient values. 


\section{Table 6: Macroeconomic Dynamics with CES-Production}

\section{Impact on Elasticity Coefficients}

Panel A. Shocks to the current workforce, $\mu_{1 \mathrm{t}}$ and $\mathrm{b}_{t-1}$ :

$$
\begin{array}{ll}
\text { Retirees: } & \pi_{\mathrm{C} 2 \mu 1}=\gamma_{\mathrm{C} 2 \mathrm{nw}}+\gamma_{\mathrm{C} 2 \beta} \cdot \pi_{\beta \mu 1}, \pi_{\mathrm{C} 2 \mathrm{~b} 1}=\gamma_{\mathrm{C} 2 \mathrm{nw}}+\gamma_{\mathrm{C} 2 \beta} \cdot \pi_{\beta \mathrm{b} 1} \\
\text { Workers: } & \pi_{\mathrm{C} 1 \mu 1}=-\Delta_{\mathrm{C}} \cdot\left[\frac{\alpha}{\varphi}-\frac{\theta}{1-\theta}\right]-\Delta_{\mathrm{C}} \cdot \frac{\theta}{1-\theta} \cdot \pi_{\beta \mu 1} \\
& \pi_{\mathrm{C} 1 \mathrm{~b} 1}=-\Delta_{\mathrm{C}} \cdot\left[\frac{\alpha}{\varphi}-\frac{\theta}{1-\theta}\right]-\Delta_{\mathrm{C}} \cdot \frac{\theta}{1-\theta} \cdot \pi_{\beta \mathrm{b} 1} \\
\text { Investment }: & \pi_{\mathrm{k} \mu 1}=-\Delta_{\mathrm{k}} \cdot\left[\frac{\alpha}{\varphi}-\frac{\theta}{1-\theta}\right]-\Delta_{\mathrm{k}} \cdot \frac{\theta}{1-\theta} \cdot \pi_{\beta \mu 1} \\
& \pi_{\mathrm{kb} 1}=-\Delta_{\mathrm{k}} \cdot\left[\frac{\alpha}{\varphi}-\frac{\theta}{1-\theta}\right]-\Delta_{\mathrm{k}} \cdot \frac{\theta}{1-\theta} \cdot \pi_{\beta \mathrm{b} 1}
\end{array}
$$

Panel B. Changes in lagged capital and productivity, $k_{t-1}$ and $a_{t}$ :

$$
\begin{array}{lll}
\text { Retirees: } & \pi_{\mathrm{C} 2 \mathrm{k}}=\gamma_{\mathrm{C} 2 \mathrm{k}}+\gamma_{\mathrm{C} 2} \cdot \pi_{\beta \mathrm{k}}, & \pi_{\mathrm{C} 2 \mathrm{a}}=-\gamma_{\mathrm{C} 2 \mathrm{k}}+\gamma_{\mathrm{C} 2 \beta} \cdot \pi_{\beta a} \\
\text { Workers: } & \pi_{\mathrm{c} 1 \mathrm{k}}=\Delta_{\mathrm{C}} \cdot \alpha / \varphi-\Delta_{\mathrm{C}} \cdot \frac{\theta}{1-\theta} \cdot \pi_{\beta \mathrm{k}}, & \pi_{\mathrm{C} 1 \mathrm{a}}=-\Delta_{\mathrm{C}} \cdot \alpha / \varphi-\Delta_{\mathrm{C}} \cdot \frac{\theta}{1-\theta} \cdot \pi_{\beta a} \\
& & \pi_{\mathrm{kk}}=\Delta_{\mathrm{k}} \cdot \alpha / \varphi-\Delta_{\mathrm{k}} \cdot \frac{\theta}{1-\theta} \cdot \pi_{\beta \mathrm{k}}, \quad \pi_{\mathrm{ka}}=-\Delta_{\mathrm{k}} \cdot \alpha / \varphi-\Delta_{\mathrm{k}} \cdot \frac{\theta}{1-\theta} \cdot \pi_{\beta a}
\end{array}
$$

\section{Notes:}

1. The notation is as in Tables 1-2, except for the following symbols:

$$
\begin{aligned}
& \alpha=\frac{\alpha_{\varphi \cdot(\mathrm{k} / \mathrm{an})} \varphi}{\alpha_{\varphi \cdot(\mathrm{k} / \mathrm{an})} \varphi+1-\alpha_{\varphi}}=\text { average capital share } \\
& \beta^{\star}=\frac{\beta \cdot(\mathrm{w} / \mathrm{A})}{\left(\mathrm{c}^{2} / \mathrm{A}\right)} /\left(1-\delta^{\star}\right)=\text { share of old income that is wage-indexed } \\
& \gamma_{\mathrm{C} 2 \mathrm{k}}=\left(1-\delta^{\star}\right) \cdot\left[\alpha+\left(1-\alpha-\beta^{\star}\right) \cdot(\varphi-1) / \varphi\right]+\delta^{\star} \\
& \gamma_{\mathrm{C} 2 \mathrm{nw}}=\left(1-\delta^{\star}\right) \cdot\left\{1-\alpha-\left(1-\alpha-\beta^{\star}\right) \cdot(\varphi-1) / \varphi-\frac{\theta \cdot(1-\alpha)}{\alpha+\theta \cdot(1-\alpha)}\right\} \\
& \pi_{\mathrm{Rk}}=\left(1-\delta / \mathrm{R}^{\mathrm{k}}\right) \cdot(1-\alpha) / \varphi
\end{aligned}
$$

2. For the impact of shocks not listed here, the formulas in Table 2 apply with the modified symbols defined here. 
Figure 1: Consumption Responses to a Birth Rate Shock

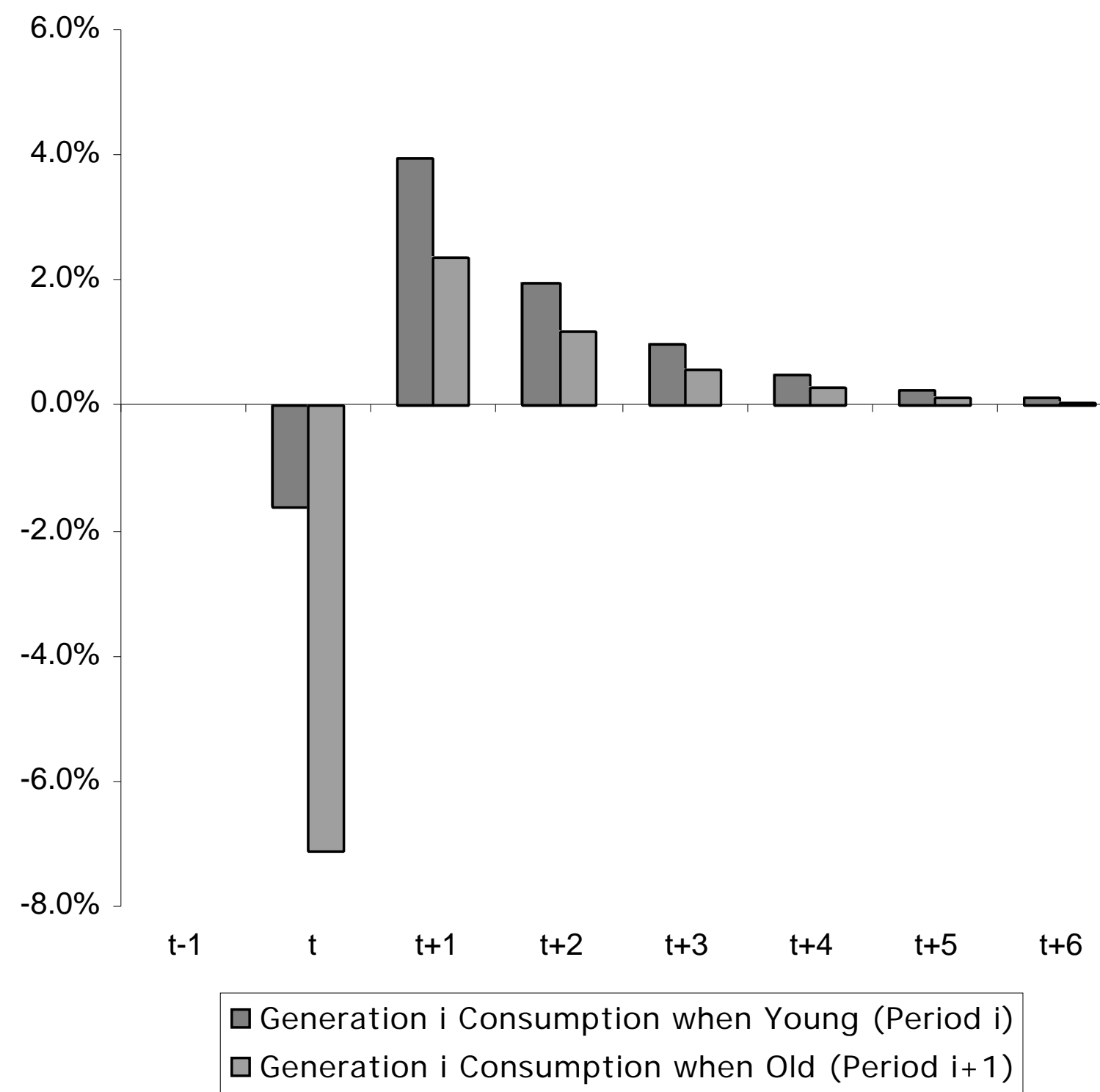

Notes: The bars show the percentage deviations of consumption from the steady state in response to a one-time, 20\% reduction in the birth rate in period $t$, applied to the parameter values of the numerical example with defined benefits social security system.

The responses are collected by generation, not by period. The responses under generation $i=t+2$ refer, e.g., to the changes in $c^{1} t+2$ (generation $t+2$ when young) and $c^{2} t+3$ (generation $t+2$ when old). 
Figure 2: Response of the Capital-Labor Ratio to a Birth Rate Shock

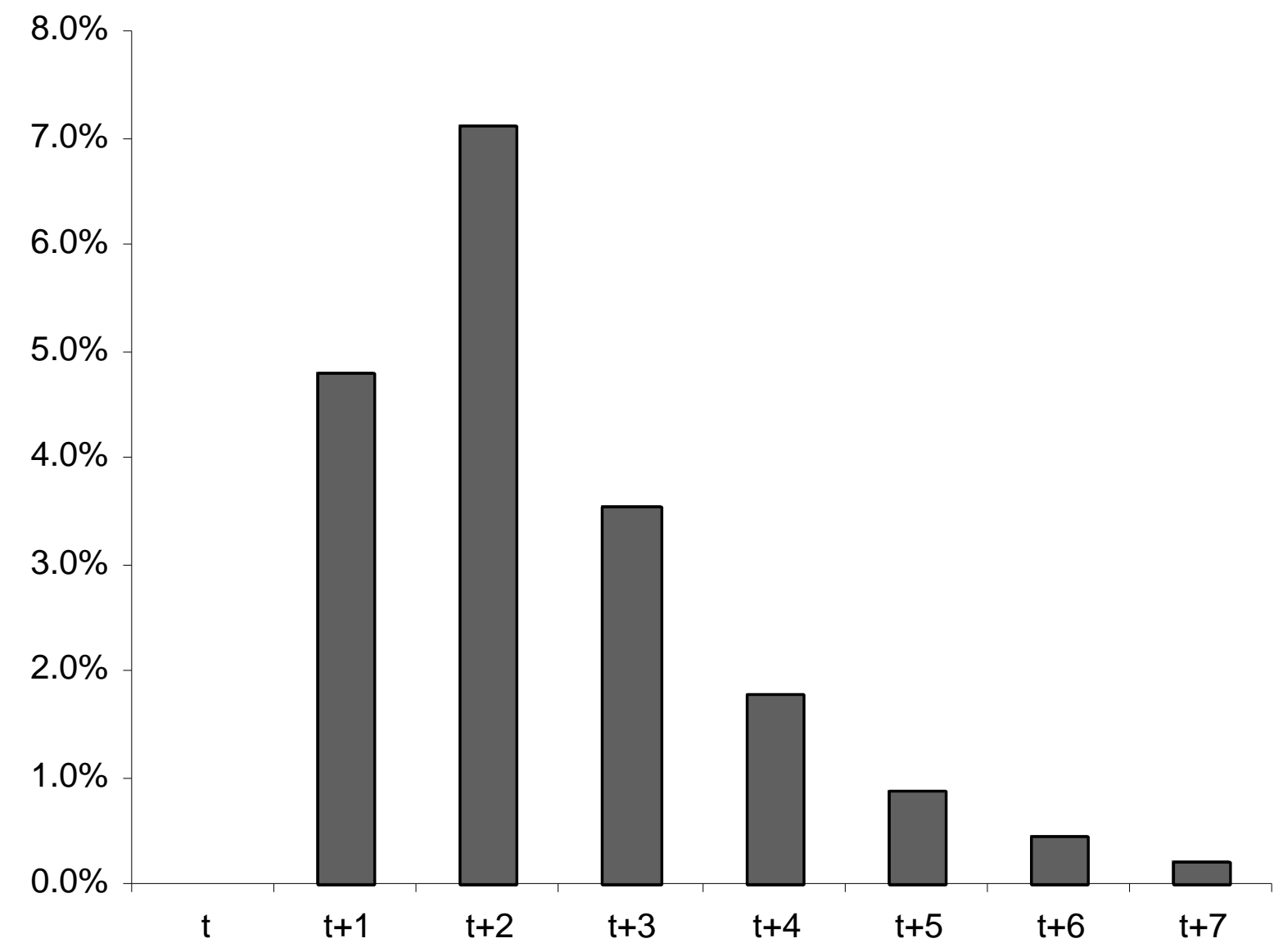

Notes: The bars show the percentage deviations of the capital labor ratio $k_{t}$ from its steady state in response to a one-time, $20 \%$ reduction in the birth rate at in period $t$, applied to the parameter values of the numerical example with defined benefits social security system. 